\title{
Avaliação das propriedades mecânicas e da flamabilidade de concretos poliméricos produzidos com resina PET e retardante de chamas reciclados
}

\author{
Use of polishing alumina as flame retardant in \\ orthophthalic polyester resin matrix composites
}

\section{Jane Proszek Gorninski Karina Guerra Tonet}

\section{Resumo}

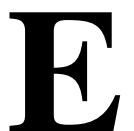

stes compósitos exibem excelentes propriedades mecânicas, mas devem ser adaptados às propriedades de combustibilidade. $\mathrm{O}$ estudo teve como objetivo, produzir concretos poliméricos utilizando alumina residual, como retardante de chamas, originados do beneficiamento industrial metalúrgico. Os compósitos tem como aglomerante a resina poliéster ortoftálica reciclada a partir do PET, como agregados foi adotada a areia de rio e a cinza volante como fíler. Foram utilizados dois tipos de retardantes de chama: um resíduo, a alumina de polimento, e o outro virgem, alumina comercial em quatro diferentes percentagens de 15, 30, 45 e 60\% em massa, em relação à resina. As amostras foram submetidas ao ensaio de resistência tração na flexão e de resistência às temperaturas de 125,225 e $325^{\circ} \mathrm{C}$. Os resultados tiveram tratamento estatístico, a fim de avaliar o nível de significância das variáveis em relação às propriedades estudadas. Os valores de resistência à tração na flexão atingiram os $30 \mathrm{MPa}$. A análise estatística mostrou que os fatores, mudanças de temperatura, percentual de adição e da interação entre esses fatores, mostraram grande influência sobre as composições estudadas em relação à resistência às temperaturas elevadas. Em termos gerais, pode dizer-se que, o retardante de chamas residual, alumina de polimento, é uma alternativa eficiente para substituir a alumina trihidratada comercial em compósitos poliméricos de resina poliéster.

Palavras-chaves: Alumina de polimento. Reciclagem. Concreto polímero. Cinza volante. Combustibilidade.

\begin{abstract}
These composites display excellent mechanical properties but must be adapted to the combustibility properties. The study aimed to produce polymer concrete composites using waste alumina from the metallurgic industrial processing. The composites have an ortophtalic polyester resin as a binder, as aggregates river sand and fly ash as filler. Two kinds of flame retardant were used: a residue, polishing alumina and the other virgin, commercial alumina in four different percentage 15, 30, 45 and $60 \%$ in mass in relation to the resin. The samples were subjected to testing of flexural strength, combustibility tests and temperature changes of 125,225 and $325^{\circ} \mathrm{C}$. Results had statistical treatment in order to evaluate the variable significance in relation to the studied properties. This study composites displayed values about $30 \mathrm{MPa}$ for flexural strength. The statistical analysis showed that the factors temperature changes, percentage of addition and the interaction among these factors posed great influence on the studied compositions in relation to the heating strength testing. In general terms, it can be said that the flame retardant waste, polishing alumina is an efficient alternative to substitute the trihydrated commercial alumina in the polymer concrete composites with the other components proposed in this study.
\end{abstract}

Recebido em 13/10/14 Aceito em 02/01/16

Karina Guerra Tonet Karina Tonet Arquitetura Porto Alegre - RS - Brasil

Keywords: Polishing alumina. Recycling. Polymer concrete. Fly ash. Combustibility. 


\section{Introdução}

A interdependência dos conceitos de meio ambiente, saúde e saneamento é hoje bastante evidente, o que reforça a necessidade de integração das ações do setor da construção civil em proveito da melhoria da qualidade de vida. O desenvolvimento de novos materiais que possuam maior resistência, durabilidade e melhor ciclo de vida está se tornando uma das principais exigências deste crescente mercado.

Os compósitos obtidos com resinas poliméricas apresentam uma propriedade que limita sua utilização em determinadas aplicações na construção civil, a sua combustibilidade (TYBERG et al., 1999; MARÍN et al., 2003; DAVIES; WANG; WONG, 2006). Esta preocupação se deve ao fato de que o desenvolvimento e duração de um incêndio são influenciados, entre outros fatores, pela quantidade e natureza dos materiais combustíveis na edificação.

Segundo Fowler (2001), os poliésteres insaturados produzidos a partir da reciclagem do PET podem ser uma fonte de resina com custo mais baixo, além de contribuir para a economia de energia. A utilização da reciclagem deste polímero para tal fim é bastante vantajosa, pois sua limpeza e a separação por cores de garrafas não precisa ser tão criteriosa, já que o produto final absorve estes componentes. Além disso, podem-se aproveitar até mesmo as unidades já depositadas nos lixões e que, por apresentarem sinais de sujeira, não serão recicladas, pois o processo de limpeza préreciclagem é oneroso (IGNÁCIO; FERRAZ; ORÉFICE, 2003).

Quanto à fase inorgânica do PC (Polymer Concrete), o agregado frequentemente utilizado é a areia de rio (ORAK, 2000; MARÍN et al., 2003; GOPAL, 2006; JO; TAE; KIM, 2007; GORNINSKI; DAL MOLIN; KAZMIERCZAK, 2007; JO; PARKS; KIM, 2008). A areia é um material já consagrado na utilização em matrizes cimentícias e poliméricas, especialmente por apresentar partículas arredondadas, o que proporciona uma melhor interação entre aglomerante e agregado (MEHTA; MONTEIRO, 1994), além de ser facilmente encontrada na maioria das regiões.

A adição de filers é normalmente associada aos compósitos poliméricos, principalmente, porque contribui tanto no aspecto mecânico quanto no químico, pois o filer colabora para a redução da porosidade do produto final (GORNINSKI, 2002). Dentre os materiais incorporados para este fim, destacam-se o carbonato de cálcio e a cinza volante.

A alumina trihidratada é um produto comercialmente utilizado como retardante de chamas para polímeros. Quando adicionada ao polímero e em contato com o fogo, a alumina se decompõe em uma reação que absorve calor e contribui com a redução da temperatura do material. A água liberada dilui os gases combustíveis na chama. A formação de óxido de alumínio $\left(\mathrm{Al}_{2} \mathrm{O}_{3}\right)$ age como uma camada protetora na superfície do material, reduzindo a difusão do oxigênio para o meio reativo, o que dificulta a troca de calor e, portanto, a propagação do fogo (RABELLO, 2000).

Frente ao exposto, e sabendo-se da existência no mercado de produtos patenteados que, quando adicionados à resina, tornam o material mais resistente ao fogo, esta pesquisa se propõe a avaliar a eficiência da adição do resíduo alumina de polimento $\left(\mathrm{Al}_{2} \mathrm{O}_{3}\right)$ para análise da combustibilidade em compósitos poliméricos (PC). A possível utilização de um resíduo como retardante de chamas, além de dar destinação a um rejeito atualmente descartado em aterros industriais, irá proporcionar à empresa geradora a possibilidade de transformá-lo em um co-produto e assim, comercializá-lo. Além disso, a empresa deixará de ter um custo mensal para o descarte deste rejeito, já que a indústria local fornecedora tem enviado cerca de 1 tonelada/mês a um aterro industrial.

Os resultados obtidos com a incorporação do resíduo alumina de polimento serão então comparados com as amostras contendo retardante de chamas de uso comercial (alumina trihidratada), a fim de obterem-se parâmetros de eficiência confiáveis.

Desta forma, os compósitos propostos neste estudo serão elaborados com elementos residuários, como é o caso do PET (resina), cinza volante (filer) e alumina de polimento (retardante de chamas), acreditando-se que esta composição possa contribuir para os estudos de novos materiais, os quais venham a colaborar para o desenvolvimento sustentável da indústria da construção civil.

\section{Materiais e métodos}

Neste item foram estudados os seguintes materiais empregados na composição do PC: areia natural utilizada como agregado, cinza volante como filer, alumina de polimento como resíduo retardante de chamas e alumina trihidratada da empresa 
Reichhold, como retardante de chamas comercial adotado como referência. $\mathrm{O}$ aglomerante utilizado neste estudo foi a resina poliéster insaturada reciclada a partir do PET, também fornecida pela Reichhold.

\section{Materiais}

\section{Resina}

Para a realização deste trabalho foi utilizada a resina poliéster insaturada obtida a partir da reciclagem do PET. De acordo com Marín et al. (2003) e Gorninski, Dal Molin e Kazmierczak (2007), a resina poliéster é um dos polímeros mais utilizados na produção de compostos poliméricos devido ao seu alto desempenho, além de resultar em um material com grande resistência mecânica e durável frente a meios agressivos, com baixa permeabilidade e de custo inferior ao da resina epóxi, também comumente utilizada em PC.

Para a composição de concreto polímero com resina reciclada, uma das propriedades a ser considerada no aglomerante é a sua viscosidade. Esta propriedade proporciona um maior poder aglomerante à resina a qual tem bom poder de molhabilidade e aglomeração ao agregado e filer, tornando a composição menos porosa, portanto com maior durabilidade e mecanicamente mais resistente. Para tal, é de fundamental importância que a resina tenha viscosidade similar à das resinas já adotadas anteriormente para este tipo de estudo. Neste caso, a viscosidade da resina obtida do resíduo PET é igual à da resina ortoftálica utilizada em estudos por Gorninski, Dal Molin e Kazmierczak (2007). As principais propriedades da resina reciclada a partir do PET que será utilizada como aglomerante neste estudo podem ser observadas na Tabela 1 , cujos dados foram fornecidos pelo fabricante Reichhold.

\section{Agregado}

Como agregado, selecionou-se para este estudo a areia de rio, pois seu emprego já é consagrado em concretos poliméricos em diversas pesquisas pelo mundo (ORAK, 2000; GOPAL, 2006; JO; TAE; KIM, 2007, 2008; GORNINSKI; DAL MOLIN; KAZMIERCZAK, 2007). Nestes trabalhos, fica claro que, devido à forma arredondada dos seus grãos, a interação entre o aglomerante polimérico e o agregado é evidenciada. Esta interação será responsável pelo desempenho mecânico apresentado pelo concreto polimérico, além da presença de mais ou menos poros, aos quais está diretamente ligada a questão da sua durabilidade e, consequentemente, do seu comportamento frente à sua resistência ao fogo, foco desta pesquisa.

A areia utilizada neste estudo é proveniente da região metropolitana de Porto Alegre/RS. Esta areia foi classificada através do ensaio de determinação da composição granulométrica, de acordo com a norma NBR NM 248 (ABNT, 2001), e então trabalhada até obter-se uma areia classificada dentro da zona ótima, conforme sugere a NBR 7211 (ABNT, 2005).

A Figura 1 mostra a distribuição granulométrica da areia a ser utilizada neste estudo, após a correção da distribuição granulométrica, além da zona utilizável.

Além desta análise, a areia foi submetida ao ensaio de massa específica, de acordo com a NM 52 (ABNT, 2002), o qual determinou o valor de 2,72 $\mathrm{g} / \mathrm{cm}^{3}$.

\section{Filer}

A cinza volante, sugerida neste estudo como filer, é um resíduo gerado pela combustão do carvão mineral em usinas termoelétricas, separados e recolhidos em precipitadores eletrostáticos ou coletores mecânicos. As cinzas de carvão compõem-se basicamente por óxidos de silício e alumínio, baixos teores em ferro e menores quantidades de $\mathrm{Mg}$, Ca, Ti, P, S, Na e K (SILVA; BUEST; CAMPITELI, 1999).

Tabela 1 - Características da resina poliéster insaturada reciclada (POLYLITE 10316 - 10)

\begin{tabular}{|c|c|c|}
\hline CARACTERÍSTICAS & $\begin{array}{l}\text { MÉTODO DE } \\
\text { ANÁLISE }\end{array}$ & ESPECIFICAÇÃO \\
\hline Viscosidade Brookfield à $25^{\circ} \mathrm{C}-(60 \mathrm{rpm}, \mathrm{Sp} 3 / \mathrm{cp})$ & PP $01-124$ & $250-350$ \\
\hline Índice de Tixotropia & PP $01-124$ & $1,15-1,40$ \\
\hline Densidade $\left(\mathrm{g} / \mathrm{cm}^{3}\right)$ & ASTM D1475 & 1.0955 \\
\hline Índice de Acidez (mgKOH/g) & PP $01-003$ & 30 máx. \\
\hline $\begin{array}{c}\text { * Curva Exotérmica à } \mathbf{2 5}^{\circ} \mathbf{C} \\
\text { Tempo de gel (minutos) } \\
\text { Intervalo simples (minutos) } \\
\text { Temperatura máxima }\left({ }^{\circ} . \mathrm{C}\right)\end{array}$ & PP $01-296$ & $\begin{array}{c}9-13 \\
8-13 \\
140-180\end{array}$ \\
\hline
\end{tabular}

Nota: *100,0 g de Resina + 1,0 ml de Peróxido de Metil Etil Cetona (PMEK - iniciador).

Fonte: Reichhold (2004). 
Figura 1 - Curva granulométrica da areia (- - - ) que foi utilizada como agregado das composições do PC

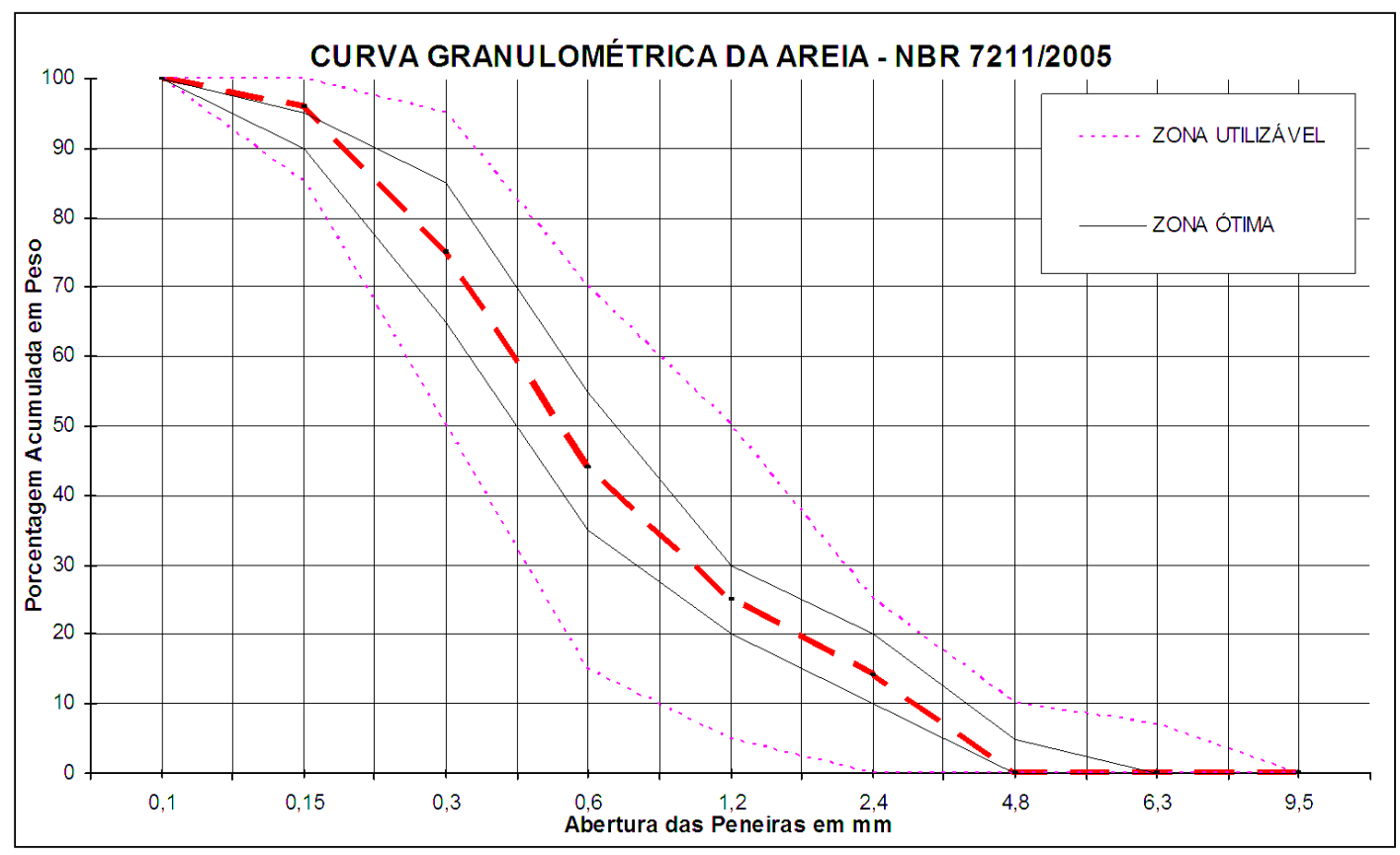

De acordo com os estudos de Gorninski e Kazmierczak (2008), a adição da cinza volante em concretos polímeros resulta em ganhos substanciais nas propriedades mecânicas deste material. A cinza volante melhora a trabalhabilidade da mistura fresca do concreto polímero e a resistência do material endurecido, além de produzir concretos com superfície de bom acabamento superficial. Estas características são provenientes do seu formato esférico que contribui com um maior fator de empacotamento entre os agregados, reduzindo a porosidade, que inibe a penetração de agentes agressivos.

Considerando-se os aspectos relevantes anteriormente dissertados, a cinza volante foi adotada neste estudo. Para tal, e por se tratar de um resíduo de baixa granulometria, a cinza volante foi submetida ao ensaio de distribuição granulométrica por difração a laser, no equipamento Cilas 1064, do Laboratório de tecnologia mineral e ambiental, da UFRGS.

A Figura 2 ilustra o resultado obtido no ensaio de distribuição granulométrica da cinza volante utilizada neste estudo.

Conforme sua distribuição granulométrica apresentada na Figura 1, observa-se que a cinza volante apresenta maior concentração de grãos na faixa entre 10 e $100 \mu \mathrm{m}$, o que a caracteriza como um material pulverulento.

A cinza volante teve sua massa específica determinada conforme a norma NM 23 (ABNT, 2000), cujo valor é $2,11 \mathrm{~g} / \mathrm{cm}^{3}$.

\section{Adições}

Retardante de chamas Alumina Trihidratada (referência comercial)

A incorporação do retardante de chama do tipo hidróxido de alumínio em matrizes poliméricas inibe a sua ignição, bem como a formação de gases combustíveis, os quais cooperam para a propagação do incêndio. Além disso, este produto garante a redução de formação de fumaça $\mathrm{e}$ monóxido de carbono, pois o hidróxido de alumínio apresenta uma degradação endotérmica. De acordo com Fu et al. (2008), a alumina trihidratada em matrizes poliméricas com base epóxi, por conter partículas pequenas, além do poder retardante, apresenta ainda uma maior proteção e resistência a fraturas, atuando como filer na composição.

Quanto ao retardante comercial que fará parte da análise comparativa deste estudo, segundo a ficha técnica disponibilizada pelo fabricante, trata-se de um hidróxido de alumínio $\left(2 \mathrm{Al}_{2}(\mathrm{OH})_{3}\right)$ desenvolvido, especificamente, para ser incorporado em sistemas poliméricos como retardante de chama e supressor de fumaça, servindo simultaneamente como material de enchimento, em substituição às cargas minerais convencionais. Além disso, este produto também apresenta significativo efeito inibidor da degradação em sistemas poliméricos utilizados como isoladores elétricos (ALCOA, 2004).

A composição e propriedades disponibilizadas pelo fabricante podem ser conferidas na Tabela 2 . 
Além destas características, o hidróxido de alumínio apresenta massa específica de $2,40 \mathrm{~g} / \mathrm{cm}^{3}$, e distribuição granulométrica conforme Figura 3.

Conforme figura 3, observa-se que a alumina trihidratada apresenta uma faixa de distribuição granulométrica ainda menor do que a cinza volante, entre 1 e $50 \mathrm{~m} \mu$, o que justifica o seu uso como filer, conforme estudo de Fu et al. (2008) e sugestão do fabricante.

Figura 2 - Distribuição granulométrica do filer cinza volante

CINZA VOLANTE

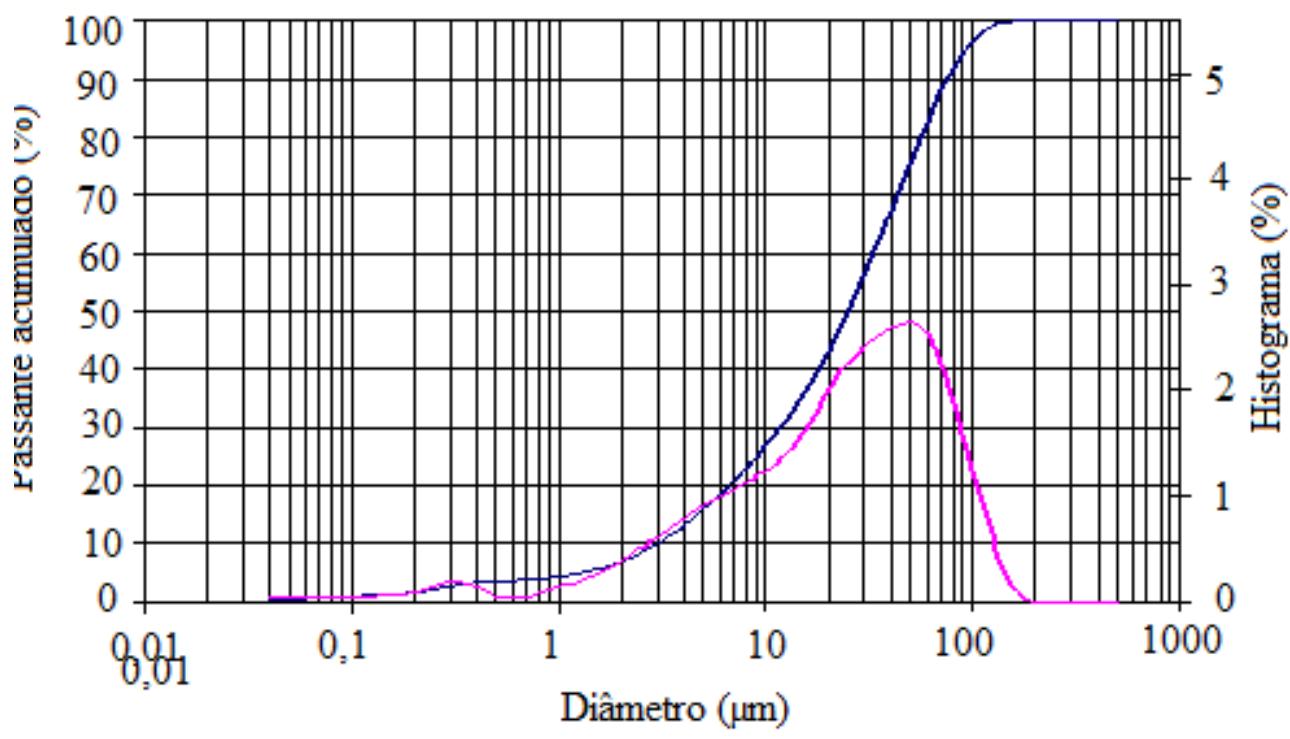

Tabela 2 - Propriedades do retardante de chamas referência (Albemarle - Reichhold)

\begin{tabular}{l|c}
\hline ANÁLISE QUÍMICA & $\%$ \\
\hline CARACTERÍSTICAS & TÍPICO \\
$\mathrm{Al}(\mathrm{OH})_{3}$ & 99,6 \\
$\mathrm{Na}_{2} \mathrm{O}-$ solúvel & 0,04 \\
Umidade $\left(105^{\circ} \mathrm{C}\right)$ & 0,25 \\
Perda ao fogo $\left(1200^{\circ} \mathrm{C}\right)$ & 34,5 \\
\hline
\end{tabular}

Fonte: Albemarle Corporation (2007).

Figura 3 - Distribuição de granulométrica da alumina trihidratada

Alumina trihidratada

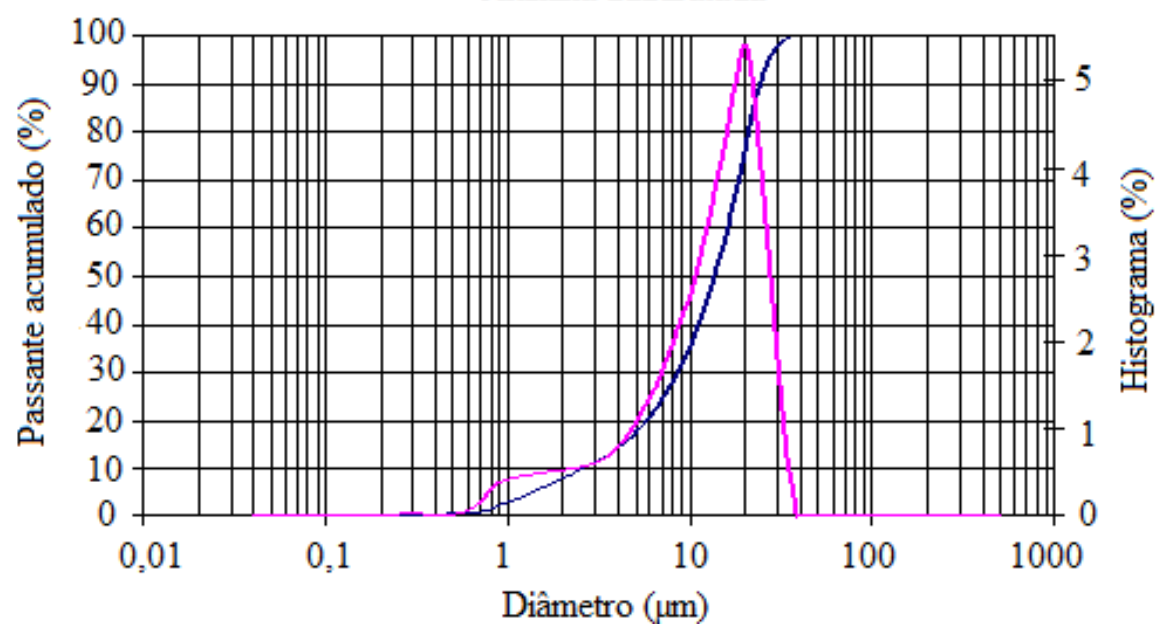




\section{Resíduo retardante de chama alumina de} polimento

A alumina $\left(\mathrm{Al}_{2} \mathrm{O}_{3}\right)$, obtida por meio de um processo controlado de calcinação do hidróxido de alumínio, apresenta grande inércia química, sendo considerada um óxido refratário pela sua capacidade de resistir a elevadas solicitações térmicas, mantendo sua natureza química. $\mathrm{Na}$ indústria, a alumina é utilizada em diversas aplicações, como: na indústria de refratários, cerâmicas e como elemento abrasivo utilizado para polimentos (ALCOA, 2007).

A alumina de polimento, propriamente dita, é composta por pequenas esferas utilizadas, principalmente, pela indústria siderúrgica, na etapa de polimento dos seus produtos. No entanto, essa etapa do processamento gera grande quantidade de resíduo, pois ao longo da sua utilização, estas esferas vão se desgastando, adquirindo um tamanho menor do que o recomendado para o processo. Além disso, as esferas acabam perdendo seu formato arredondado, criando arestas e sendo então inapropriadas para o processo de polimento. Com isso, a alumina torna-se um resíduo e necessita ser descartada adequadamente em aterros industriais.

De uso consagrado como retardante de chamas, a alumina trihidratada $\left(2 \mathrm{Al}_{2}(\mathrm{OH})_{3}\right)$ é adicionada a polímeros para reduzir sua combustibilidade, umas das propriedades limitantes do uso deste tipo de material em aplicações estruturais. Dentro da composição deste retardante, segundo Rabello (2000), formado por água e óxido de alumínio $\left(\mathrm{Al}_{2} \mathrm{O}_{3}\right)$, este elemento, quando em contato com o calor em uma situação de incêndio, age formando uma camada protetora na superfície do substrato a ser protegido, reduzindo a difusão do oxigênio para o meio reativo, o que dificulta a troca de calor e, portanto, a propagação do fogo.

Frente ao exposto, o resíduo da alumina de polimento foi então adicionado aos compósitos poliméricos propostos neste estudo, para testar sua eficiência como retardante de chamas. Para tal, este resíduo foi submetido a ensaios de caracterização física de análise granulométrica e caracterização química. A sua distribuição granulométrica foi executada por difração a laser no mesmo equipamento utilizado para a realização deste ensaio para a cinza volante, Cilas 1064. O resultado obtido está demonstrado na Figura 4.

Em comparação com a granulometria da alumina trihidratada (referência comercial) apresentada na Figura 4, fica claro que, apesar de ser um material muito fino, o resíduo da alumina de polimento apresenta uma maior fração de grãos concentrados em uma faixa granulométrica maior, neste caso, entre 50 e $500 \mu \mathrm{m}$. Considerando-se esta diferença entre as granulometrias apresentadas pelos dois retardantes, o resíduo e o comercial, optou-se por peneirar a alumina de polimento. Com isso, somente o volume passante pela peneira de $75 \mu \mathrm{m}$. Esta peneira foi adotada para que fosse possível ampliar a semelhança entre os retardantes de chama que foram comparados, bem como com o fíler, com a intenção de gerar o menor volume possível de resíduo não utilizado, e que foi então descartado (acima de $75 \mu \mathrm{m}$ ).

Após o processo de peneiramento, o resíduo alumina de polimento foi submetido novamente à distribuição granulométrica por difração a laser, no mesmo equipamento supracitado, e apresentou a seguinte curva, conforme Figura 5.

Figura 4 - Distribuição granulométrica do resíduo alumina de polimento antes da peneiração

Alumina (original)

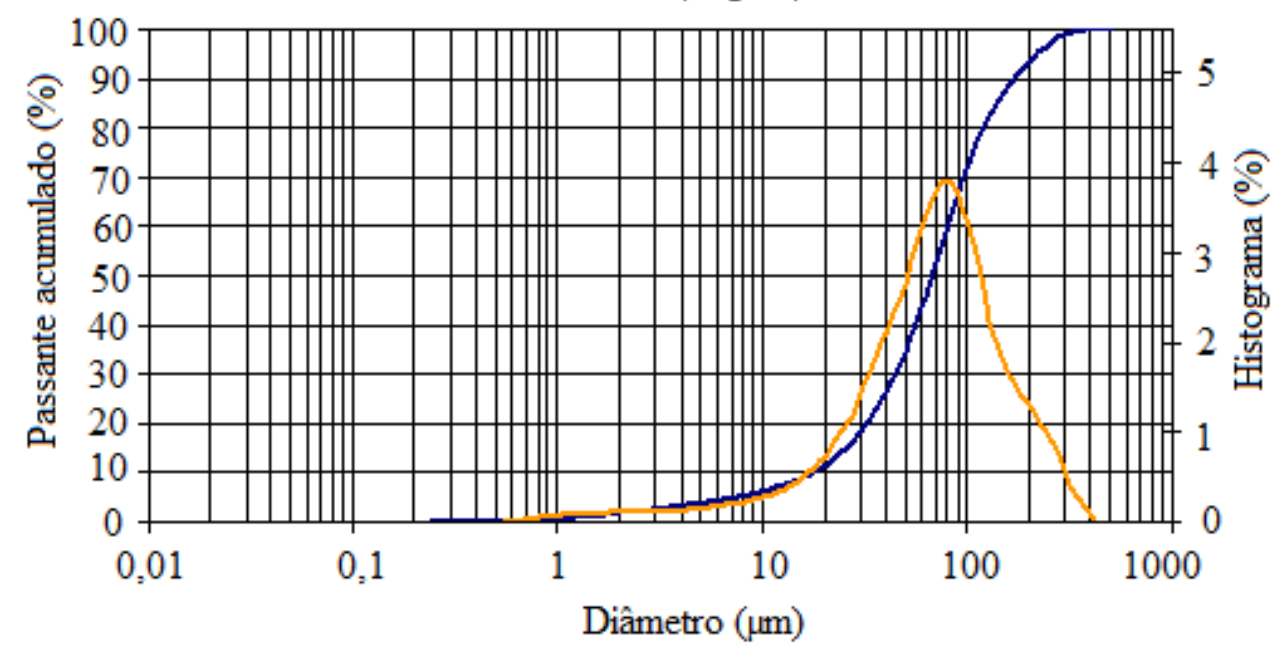

74 Gorninski, J. P.; Tonet, K.G. 
Figura 5 - Distribuição granulométrica do resíduo alumina de polimento após Peneiramento

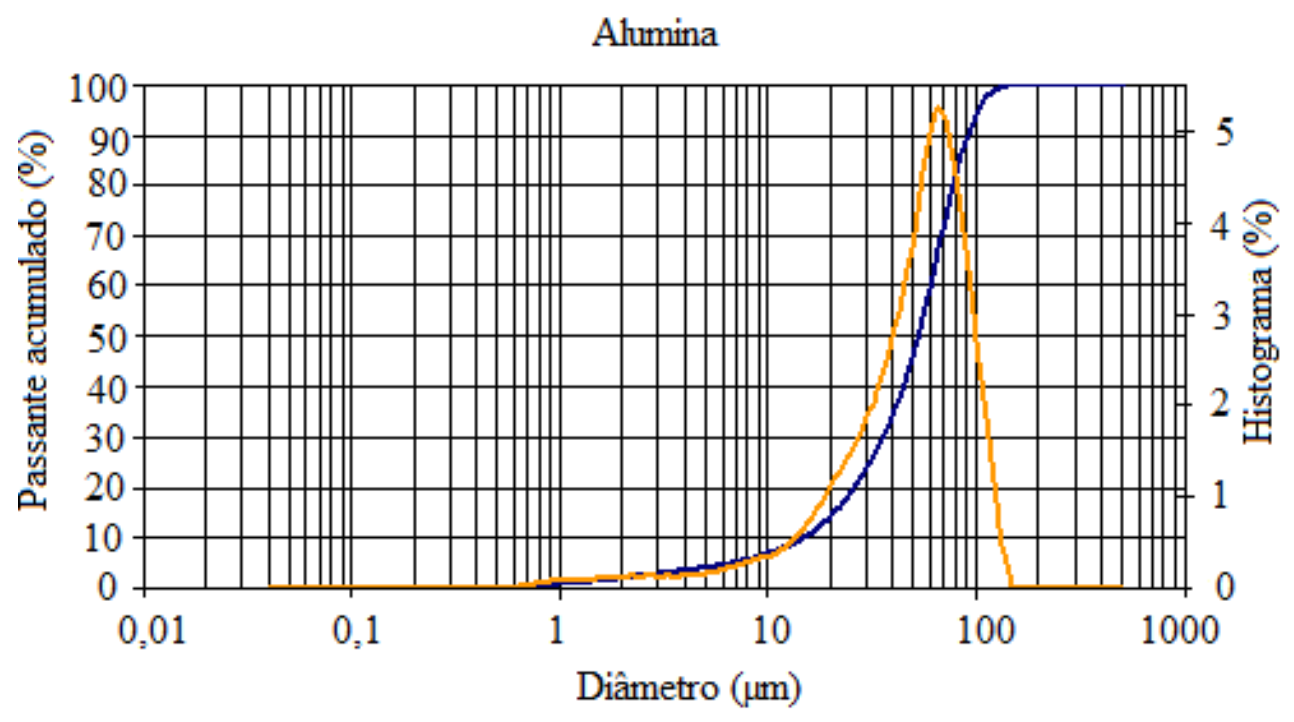

Após o peneiramento, a curva granulométrica da alumina de polimento apresentou maior concentração de grão entre 10 e $100 \mathrm{~m} \mu$, ainda maior que a alumina trihidratada, mas similar à distribuição granulométrica da cinza volante.

Além deste, a alumina de polimento teve sua massa específica determinada conforme a norma NM 23 (ABNT, 2000), cujo valor é 4,54 g/cm 3 . Em comparação com a alumina trihidratada, cujo valor obtido é de $2,40 \mathrm{~g} / \mathrm{cm}^{3}$, observa-se que o valor da massa específica da alumina de polimento é consideravelmente maior. Esta diferença pode estar relacionada à presença de metais na composição deste resíduo.

Para conhecimento da composição química do resíduo alumina de polimento, este componente foi submetido ao ensaio de fluorescência de raios X.

No caso desta pesquisa, este ensaio foi realizado pelo sistema de dispersão por comprimento de onda, no laboratório do GEPSI (Grupo de Estudos de Propriedades de Superfícies e Interfaces). A preparação das amostras foi realizada em bolachas sinterizadas em resina epóxi (aralditeTM), e então analisadas no aparelho Shimadzu Lab Center XRF 1800 Spectrometer.

Os resultados obtidos no ensaio de fluorescência de raios X está demonstrado na Tabela 3, onde são apontados os elementos componentes do resíduo, bem como as quantidades encontradas neste

Observa-se na Tabela 3 que os elementos encontrados nas amostras de antes do processo e depois do processo de polimento das ferramentas nas máquinas da empresa são os mesmos. Porém, alguns elementos como alumínio, enxofre, ferro, silício e potássio apresentaram um aumento de quantidade após o processo de polimento, o que corresponde, provavelmente, à incorporação no resíduo dos elementos presentes nas ligas metálicas ou impurezas das ferramentas polidas. Vale salientar que as percentagens dos elementos apresentados neste ensaio referem-se aos metais constituintes do resíduo, mas que, na sua composição, aparecem na forma de óxidos, como por exemplo: alumínio $\left(\mathrm{Al}_{2} \mathrm{O}_{3}\right)$, sódio $\left(\mathrm{Na}_{2} \mathrm{O}\right)$, ferro $\left(\mathrm{Fe}_{2} \mathrm{O}_{3}\right)$, etc.

De acordo com o fabricante da alumina de polimento, este material apresenta $0,2 \%$ de umidade $\left(300^{\circ} \mathrm{C}\right)$ e perda ao fogo de $0,5 \%$ (300$\left.1000^{\circ} \mathrm{C}\right)(\mathrm{ALCOA}, 2004)$.

Em comparação com as propriedades da alumina trihidratada apresentada na Tabela 2, observa-se que ambos são compostos por óxido de alumínio em grande parte, e por outros óxidos em menor quantidade. Porém, a alumina trihidratada apresenta água em sua composição, diferente da alumina de polimento que não a possui.

\section{Métodos}

\section{Mistura, moldagem e cura}

Primeiramente, o agregado, filer e adições foram mantidos em estufa à $60^{\circ} \mathrm{C}$ por 24 horas para secagem. Após, iniciaram-se as misturas das composições com o auxílio de uma argamassadeira de eixo vertical. No processo de mistura, inicialmente foram misturados todos os materiais inorgânicos (agregado, filer e adição) e então foi colocada a resina a qual já foi previamente misturada ao catalisador. 
Tabela 3 - Análise química da alumina de polimento antes e após o processo de polimento, obtida através do ensaio de fluorescência de raios $X$

\begin{tabular}{c|c|c}
\hline Elemento químico & $\begin{array}{c}\text { \% ANTES do processo de } \\
\text { polimento }\end{array}$ & $\begin{array}{c}\text { \% APÓS o processo de } \\
\text { polimento }\end{array}$ \\
\hline Alumínio & 54,5 & 63,2 \\
Zircônio & 18,9 & 10,9 \\
Sódio & 13,8 & 8,9 \\
Enxofre & 0,8 & 3,9 \\
Silício & 1,7 & 3,6 \\
Ferro & 0,8 & 3,3 \\
Potássio & 1,9 & 2,2 \\
Cloro & 4,2 & 1,9 \\
Titânio & 1,4 & 1,1 \\
Cálcio & 0,6 & 0,6 \\
Estrôncio & 1,4 & 0,4 \\
\hline
\end{tabular}

As moldagens seguiram as especificações da NBR 5738 (ABNT, 1994). Neste estudo, utilizou-se a estufa para processo de cura a fim de manterem-se controlados os parâmetros de temperatura e umidade, descartando-se a cura em temperatura ambiente. Após moldagem, os corpos-de-prova foram colocados em estufa a $50^{\circ} \mathrm{C}$ por 3 horas, e então foram desmoldados. Voltando à estufa, os corpos-de-prova foram mantidos por mais 7 dias, e então retirados e mantidos em temperatura ambiente $\left( \pm 23^{\circ} \mathrm{C}\right)$ até serem então ensaiados.

\section{Metodologia dos ensaios para o PC}

Para atingir os objetivos deste estudo, principalmente no que diz respeito ao comportamento dos compósitos poliméricos frente à ação do fogo, foram selecionados os seguintes ensaios que compuseram o programa experimental desta pesquisa: ensaio de resistência mecânica (à tração na flexão), ensaios de combustibilidade (ensaio de resistência ao calor e à propagação de chamas).

\section{Ensaio de resistência mecânica: resistência à tração na flexão}

Este ensaio foi executado no mesmo laboratório e prensa (modelo: Emic, cap. $2.000 \mathrm{KN}$ ), de acordo com a norma NBR 12142 (ABNT, 1991). Para cada teor de adição investigado foram ensaiadas três amostras.

\section{Ensaios de combustibilidade: ensaio de resistência ao calor}

Para a determinação das temperaturas de exposição do concreto polímero, realizaram-se ensaios preliminares em forno. Primeiramente, foram ensaiadas amostras representativas em temperaturas intervaladas, a cada acréscimo de $100^{\circ} \mathrm{C}$, até estabelecerem-se as temperaturas máximas de suporte ao calor imediatamente antes de apresentarem sinais de degradação ou emissão de fumaça e gases. Desta forma, a amostra de referência, sem adições de cargas retardantes, iniciou a propagação de fumaça aos $350^{\circ} \mathrm{C}$. Apesar das amostras com adições terem suportado temperaturas maiores (aproximadamente $470^{\circ} \mathrm{C}$ ), para que nenhuma amostra apresentasse sinais evidentes de combustão, as temperaturas adotadas para este ensaio foram: $125^{\circ} \mathrm{C}, 225^{\circ} \mathrm{C}$ e $325^{\circ} \mathrm{C}$, sendo que para cada temperatura, foram ensaiadas duas amostras de cada composição.

$\mathrm{O}$ ensaio preliminar e o ensaio definitivo foram conduzidos em forno tipo câmara, marca Brasimet, modelo K250n2. A velocidade de aquecimento utilizada foi de 10 a $15^{\circ} \mathrm{C}$ por minuto, e uma potência de 7,7 Kw.

Os resultados obtidos nos ensaios do programa experimental foram analisados, estatisticamente, com aplicação de software específico para análise estatística (SPSS), utilizando o método Tukey HSD para análise de variância (ANOVA). Esta análise compara, de forma estatística, a influência de cada fator estudado na experiência, ao mesmo tempo em que confere qualquer interação existente entre eles. Neste estudo, a análise estatística adotou-se um nível de confiança de $95 \%$.

\section{Dosagens do programa experimental}

De acordo com estudos realizados em concretos poliméricos, os teores comumente empregados para o aglomerante variam entre 10 e $20 \%$ em relação à massa total do agregado e filer (REBEIZ, 1995; GORNINSKI, 1996; ORAK, 2000; ABDEL-FATTAH; EL-HAWARY, 1999 ; BINOZZI; SACCANI; SANDROLINI, 2000; GOPAL, 2006; MAHDI; KHAN; ABBAS, 2007; GORNINSKI; DAL MOLIN; KAZMIERCZAK, 2007). Porém, sendo o aglomerante polimérico o maior responsável pela flamabilidade do PC, 
quanto menor o teor utilizado na composição, melhor deverá ser seu desempenho frente à ação do calor.

Além da determinação do teor de aglomerante, para que ocorra o processo de polimerização da resina e seu consequente endurecimento, é necessário adicionar-se o iniciador (catalisador). Neste caso, o produto a ser adicionado é o Peróxido de Metil Etil Cetona (PMEK), cujo teor de $1 \%$ foi escolhido conforme adotado em pesquisas semelhantes (REBEIZ, 1995; JO; TAE: KIM, 2007; GORNINSKI et al., 2007; GORNINSKI; DAL MOLIN; KAZMIERCZAK, 2004).

De acordo com as dosagens de adições já estudadas na metodologia apresentada por Trombini (2004), os teores de adição dos retardantes de chama não devem ultrapassar a porcentagem de $60 \%$ (no caso da resina pura) em relação à massa do aglomerante para que não comprometa a resistência mecânica do compósito. Porém, como não se tem registros do comportamento do residuo alumina de polimento em PC, o valor máximo adotado para este estudo preliminar foi de $40 \%$, visto que no caso do PC existem outros componentes inorgânicos além da adição do retardante de chamas. Para que se comprove a função filer da cinza volante, o estudo preliminar também averiguou o desempenho mecânico de compósitos sem sua adição.

O programa experimental se propôs a avaliar as seguintes composições do PC, conforme demonstra a Tabela 4.

\section{Apresentação e análise dos resultados}

Neste capítulo serão apresentados os resultados obtidos nos ensaios de resistência mecânica, de combustibilidade e a análise da microestrutura, bem como a discussão destes dados e análise estatística dos mesmos. Para a compreensão dos valores obtidos, serão utilizadas as seguintes convenções:

(a) REF. - amostras produzidas sem adições de retardantes, somente com agregado e filer;

(b) $\mathbf{R}$ - amostras produzidas com agregado, fíler e adição de Resíduo alumina de polimento; e

(c) $\mathbf{A}$ - amostras produzidas com agregado, fíler e adição de Alumina trihidratada.

Nas tabelas que apresentam os resultados, os números 15, 30, 45 e 60 correspondem ao percentual de adição em relação à massa da resina empregados nas composições. As siglas $\mathbf{S}$ e CV correspondem a desvio padrão e coeficiente de variação, consecutivamente.

Neste item, são também discutidos os resultados dos dados analisados estatisticamente com aplicação de software específico para estatísticas (SPSS), utilizando o método Tukey HSD para análise de variância (ANOVA). Os dados foram testados com o teste de Shapiro-Wilk e apresentaram normalidade com valores maiores que 0,05 .

Tabela 4 - Composições de concreto polímero utilizadas

\begin{tabular}{|c|c|c|}
\hline $\begin{array}{l}\text { Componentes do } \\
\text { concreto polímero }\end{array}$ & Composição & Massa $(\%)$ \\
\hline a) Resina & Poliéster insaturado de PET reciclado & $17^{\mathrm{b}}$ \\
\hline $\begin{array}{l}\text { Promotor } \\
\text { Iniciador }\end{array}$ & \multirow[t]{2}{*}{$\begin{array}{l}\text { Naftenato de cobalto } \\
\text { Peróxido de metil etil cetona (PMEK) }\end{array}$} & $1.0^{\mathrm{a}}$ \\
\hline & & $1.0^{\mathrm{a}}$ \\
\hline b) Agregado & Areia de rio & $100 \%$ dos demais materiais \\
\hline c) Filer & Cinza volante & $6^{\mathrm{c}}$ \\
\hline d) Adições & $\begin{array}{l}\text { Resíduo Alumina de polimento } \\
\text { Alumina trihidratada }\end{array}$ & $\begin{array}{l}0,15,30,45 \text { e } 60^{a} \\
0,15,30,45 \text { e } 60^{a}\end{array}$ \\
\hline
\end{tabular}


Neste trabalho, são consideradas variáveis dependentes os dados gerados nos ensaios de resistência mecânica, na avaliação de perda de resistência e de massa após a permanência das amostras em forno, bem como o tempo de propagação de chamas. Para a análise, foi adotado um nível de significância $(\alpha)$ igual a 0,05 . Nas tabelas apresentadas a seguir, são utilizadas as siglas:

(a) GDL = grau de liberdade;

(b) MQ = média quadrada (= SQ/GDL);

(c) $\mathbf{F}=\mathrm{MQ} / \mathrm{MQErro}$ (efeito da interação entre os fatores);

(d) $\mathbf{S}=$ significância;

(e) $\mathbf{S I}=$ significativo;

(f) $\mathbf{N S}=$ não significativo; e (g) REF: composições que não possuem retardantes de chama na composição.

Através do fator $\mathbf{S}$ pode-se conhecer a significância dos fatores ou da interação entre os mesmos. Se o valor obtido para este fator for menor do que 0,05 , a interação é considerada significativa, exercendo então um efeito sobre a resposta.

\section{Ensaios de resistência mecânica}

\section{Resistência à tração na flexão: resultados e discussão}

Na Tabela 5 e na Figura 6 estão apresentados os três resultados parciais e as médias para os ensaios de resistência à tração na flexão, bem como o desvio padrão e os coeficientes de variação encontrados.

Tabela 5 - Resistência à tração na flexão - programa experimental

\begin{tabular}{c|c|c|c|c|c|c}
\hline $\mathbf{C P}$ & $\mathbf{0 1}$ & $\mathbf{0 2}$ & $\mathbf{0 3}$ & MÉDIA & S (MPa) & CV (\%) \\
\hline $\mathbf{R - 1 5}$ & 34,8 & 29,2 & 30,7 & 31,6 & 2,89 & 8,40 \\
\hline $\mathbf{R - 3 0}$ & 23,6 & 29,6 & 24,4 & 25,9 & 3,25 & 10,61 \\
\hline $\mathbf{R - 4 5}$ & 31,9 & 31,9 & 31,1 & 31,6 & 0,46 & 0,21 \\
\hline $\mathbf{R - 6 0}$ & 32,2 & 32,2 & 29,2 & 31,2 & 1,73 & 3,00 \\
\hline $\mathbf{A - 1 5}$ & & & & & & \\
\hline $\mathbf{A - 3 0}$ & 25,5 & 22,5 & 25,5 & 24,5 & 1,73 & 3,00 \\
\hline $\mathbf{A - 4 5}$ & 31,5 & 31,9 & 31,2 & 31,9 & 0,35 & 0,12 \\
\hline $\mathbf{A - 6 0}$ & 31,9 & $*$ & 39,2 & 30,5 & 1,90 & 3,64 \\
\hline $\mathbf{R E F}$ & & & & & & \\
\hline
\end{tabular}

Nota: *falha na ruptura do corpo-de-prova.

Figura 6 - Dados obtidos no ensaio de resistência à tração na flexão de acordo com o tipo e teor da adição

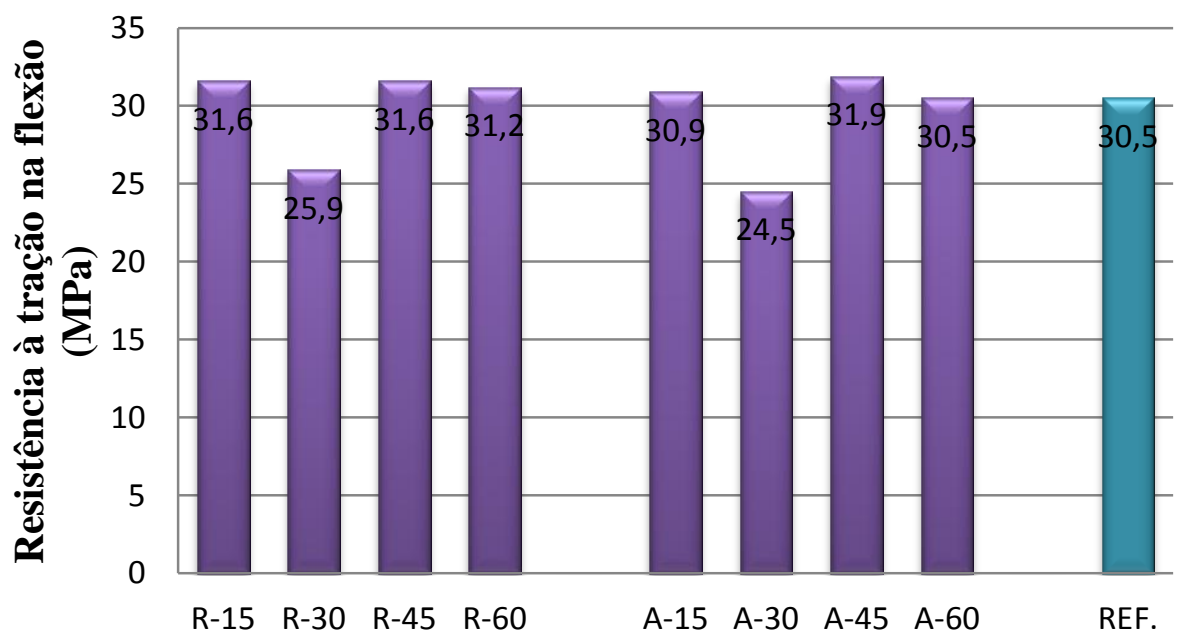

Tipo e teor das adições (\%) 
Os compósitos apresentaram comportamentos semelhantes independente do tipo de adição empregado neste ensaio de tração na flexão. Em geral, os valores encontrados na literatura pesquisada para esta resistência apresentam-se em torno dos $20 \mathrm{MPa}$, dependendo da composição proposta (REBEIZ, 1995; GORNINSKI; DAL MOLIN; KAZMIERCZAK, 2007; RODRIGUES, 2007; GORNINSKI; KAZMIERCZAK, 2008, JO; TAE; KIM, 2008). Observa-se, entretanto, que os valores encontrados neste estudo foram superiores aos encontrados na literatura, inclusive para os compósitos com $30 \%$ de retardante, os quais neste caso, apresentaram os menores valores para os esforços de tração na flexão.

No estudo de Gorninski, Dal Molin e Kazmierczak (2007), os compósitos com 13\% da resina poliéster ortoftálica virgem (mesma viscosidade da resina de PET) e $8 \%$ de cinza volante apresentaram valores inferiores $(17,9 \mathrm{MPa})$ para a resistência à tração na flexão se comparado aos resultados obtidos neste estudo. Conforme os autores foram adicionando cinza volante ao PC, a resistência de tração na flexão aumentou para 20,5 MPa, com 20\% de adição deste filer. De qualquer maneira, observa-se que, no caso deste estudo, os valores apresentaram-se, na média, em $30 \mathrm{MPa}$, exceto pelos compósitos com $30 \%$ de adição de retardante, os quais mostraram uma resistência mecânica aproximadamente $15 \%$ inferior. Apesar deste fato, nota-se que, mesmo demonstrando $15 \%$ a menos de resistência à tração na flexão, tanto os compósitos com adição de retardante resíduo alumina de polimento quanto os PC com adição de retardante comercial obtiveram resultados superiores aos encontrados na literatura pesquisada (REBEIZ, 1995; GORNINSKI; DAL MOLIN; KAZMIERCZAK, 2007; GORNINSKI; KAZMIERCZAK, 2008; JO; TAE; KIM, 2008).

Bignozzi, Saccani e Sandrolini (2000) desenvolveram um estudo com concreto polimérico composto por resina poliéster ortoftálica, agregado areia natural, carbonato de cálcio e resíduos poliméricos para utilização como filer. Neste estudo, os autores obtiveram valores similares aos apresentados nesta pesquisa, variando entre 25 e $31 \mathrm{MPa}$, conforme o tipo de material polimérico utilizado como filer. De qualquer maneira, vale salientar que, no caso do presente estudo, além de tratar-se de uma composição com uso de uma resina reciclada, a qual colabora para o desenvolvimento de materiais ecologicamente corretos para a indústria da construção civil, os compósitos ainda apresentam uma resistência à ação do calor e do fogo, propriedade deficitária dos concretos poliméricos.

\section{Resistência à tração na flexão: análise estatística}

A Tabela 6 apresenta os resultados originados na análise de variância onde puderam ser conhecidos os fatores significativos na propriedade de resistência à tração na flexão.

A Figura 7 ilustra o comportamento dos compósitos com adição de retardante resíduo e retardante comercial, bem como o compósito referência no ensaio de resistência à tração na flexão.

A análise estatística apresentada na Tabela 6 indica que há diferenças significativas entre os teores das adições utilizadas $(\alpha=0,001735)$, porém demonstra que não há significância quanto ao tipo de adição utilizado $(\alpha=0,936588)$, bem como na interação entre estes fatores $(\alpha=0,894872)$. Este comportamento também pode ser notado no caso da resistência à compressão dos compósitos.

Conforme se observa na Figura 7, as duas adições de retardantes de chama utilizadas, tanto o residuo alumina de polimento quanto o retardante comercial (alumina trihidratada) apresentaram um comportamento semelhante, sem muita variação entre os teores, exceto no teor de $30 \%$. Por este motivo, acredita-se que a análise de variância tenha apresentado significância quanto ao teor de adição empregado, independente do tipo de adição utilizado.

Tabela 6 - Análise de variância da resistência à tração na flexão

\begin{tabular}{c|c|c|c|c|c|c}
\hline VARIÁVEL & GLD & SQ & MQ & F & S & SIGNIFIC. \\
\hline $\begin{array}{c}\text { Teor de } \\
\text { adição (A) }\end{array}$ & 4 & 14,25844 & 0,35434029 & 40,23939 & 0,001735 & SI \\
\hline $\begin{array}{c}\text { Tipo de } \\
\text { adição (B) }\end{array}$ & 2 & 0,631285 & 9,53142357 & 0,066232 & 0,936588 & NS \\
\hline $\begin{array}{c}\text { Interação } \\
\text { (AB) }\end{array}$ & 5 & 0,646493 & 0,21549769 & 0,596872 & 0,894872 & NS \\
\hline Erro & 12 & 8,713628 & 1,002373 & - & - & - \\
\hline
\end{tabular}


Figura 7 - Médias observadas no ensaio de resistência à tração na flexão dos compósitos com adição de resíduo, retardante comercial e amostra referência

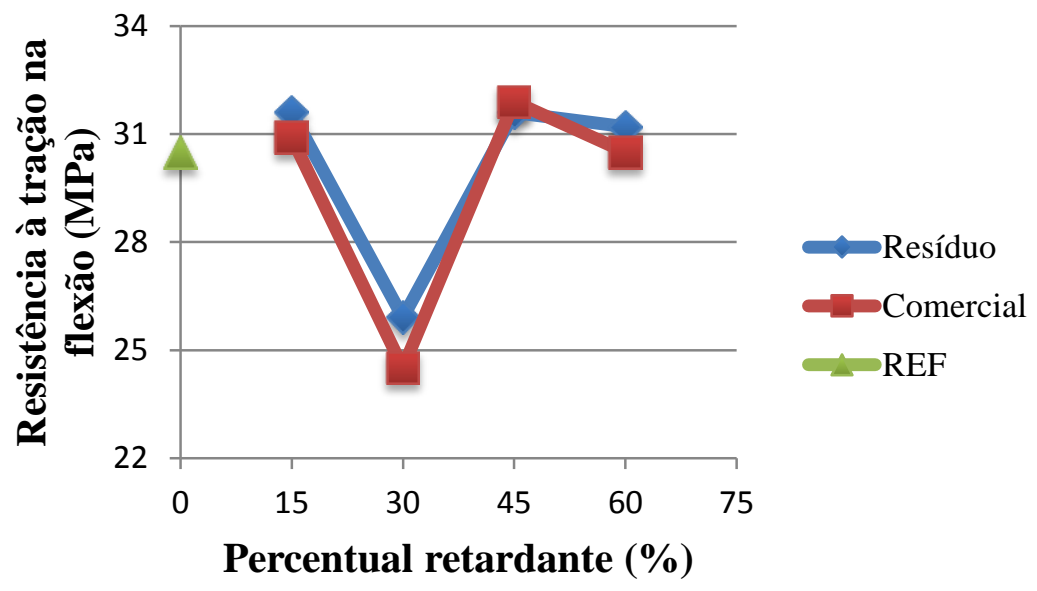

Desta forma, e tendo-se em vista a similaridade de comportamento apresentada pelos compósitos com os dois diferentes tipos de adição, sugere-se que o retardante resíduo alumina de polimento possa ser utilizado em substituição ao retardante comercial alumina trihidratada, mantendo a eficiência do mesmo, no que diz respeito ao comportamento mecânico do Concreto Polímero.

\section{Ensaios de combustibilidade}

\section{Ensaio de resistência ao calor: resultados e discussão}

Após ensaios preliminares para a determinação das temperaturas limites de exposição dos compósitos neste estudo apresentado, os corpos-de-prova foram submetidos às temperaturas de $125^{\circ} \mathrm{C}$, $225^{\circ} \mathrm{C}$ e $325^{\circ} \mathrm{C}$, sendo ensaiadas duas amostras de cada composição para cada temperatura. Cada duas amostras de cada composição (R15, R30, R45, R60, A15, A30, A45, A60 e REF.) foram mantidas em cada uma das temperaturas por uma hora. Após serem retirados, os corpos-de-prova foram colocados em sala climatizada por 72 horas e então avaliados no ensaio de resistência à tração na flexão. A Tabela 7 e a Figura 8 apresentam as médias obtidas neste ensaio de resistência mecânica para cada composição após permanência em forno nas temperaturas supracitadas. A Figura 8 apresenta ainda a média obtida para o ensaio de resistência à tração na flexão para os compósitos não submetidos ao forno, apenas mantidos em sala climatizada, os quais foram denominados, na legenda, como tração na flexão ambiente.

A Figura 8 apresenta ainda a média obtida para o ensaio de resistência à tração na flexão para os compósitos não submetidos ao forno, apenas mantidos em sala climatizada, os quais foram denominados, na legenda, como tração na flexão ambiente.

De acordo com a Tabela 7 e a Figura 8, observa-se que os compósitos R30, R45, R60, A15, A30 e A60 apresentaram um aumento na resistência à tração na flexão após terem sido expostos à temperatura de $125^{\circ} \mathrm{C}$ por 1 hora. Sugere-se esta temperatura tenha submetido as amostras a um processo de pós-cura, o que geralmente favorece o aumento da resistência dos polímeros. Esta conclusão também foi apresentada na pesquisa de Pinto et al. (2005) o qual observou que a exposição térmica de seus compósitos poliméricos, em estufa de circulação forçada de ar operando a $110^{\circ} \mathrm{C}$ em tempos curtos (até 4 dias), promoveu aumentos na resistência mecânica, os quais foram atribuídos a reações de pós-cura.

Os fabricantes de resinas poliésteres insaturadas sugerem que o processo de pós-cura nos compósitos deva ser feito, via de regra, à temperatura de 60 a $80^{\circ} \mathrm{C}$ (ARAASHLAND, 2008; REICHHOLD, 2004). Esta especificação dos fabricantes aplica-se à resina quando utilizada de forma pura, sem agregados, diferente do caso do PC. Neste estudo, os elementos inorgânicos, incluindo agregado, filer e adições, elevam a temperatura de pós-cura dos compósitos. De qualquer maneira, observa-se que na temperatura de $125^{\circ} \mathrm{C}$, este processo de ganho de resistência mecânica ocorreu somente nos compósitos com adição de retardante, pois o mesmo manteve a temperatura dos compósitos reduzida, tornando a condição ideal para que ocorresse a pós-cura nestes casos. Este fato não ocorreu no compósito referência, o qual apresentou perda de resistência já após a exposição à $125^{\circ} \mathrm{C}$. 
Tabela 7 - Médias obtidas para a resistência à tração na flexão de cada composição após as amostras serem submetidas às temperaturas de $125^{\circ} \mathrm{C}, 225^{\circ} \mathrm{C}$ e $325^{\circ} \mathrm{C}$ - programa experimental

\begin{tabular}{c|c|c|c|c|c}
\hline $\mathbf{C P}$ & $\begin{array}{c}\text { MÉDIA EM } \\
\text { TEMP. } \\
\text { AMBIENTE }\end{array}$ & $\begin{array}{c}\text { MÉDIA } \mathbf{A} \\
\mathbf{1 2 5}^{\circ} \mathbf{C}\end{array}$ & $\begin{array}{c}\text { MÉDIA } \mathbf{A} \\
\mathbf{2 2 5}^{\circ} \mathbf{C}\end{array}$ & $\begin{array}{c}\text { MÉDIA À } \\
\mathbf{3 2 5}^{\circ} \mathbf{C}\end{array}$ & $\begin{array}{c}\text { Perda de Ft da } \\
\text { temperatura } \\
\text { ambiente para } \\
\mathbf{3 2 5}^{\circ} \mathbf{C}(\boldsymbol{\%})\end{array}$ \\
\hline $\mathbf{R - 1 5}$ & 31,6 & 31,1 & 20,8 & 18,7 & 40,8 \\
\hline $\mathbf{R - 3 0}$ & 25,9 & 29,2 & 22,5 & 22,9 & 11,5 \\
\hline $\mathbf{R - 4 5}$ & 31,6 & 32,6 & 24,7 & 21,4 & 32,2 \\
\hline $\mathbf{R - 6 0}$ & 31,2 & 34,5 & 29,1 & 23,0 & 26,3 \\
\hline $\mathbf{A - 1 5}$ & 30,9 & 31,5 & 25,7 & 20,4 & 33,9 \\
\hline $\mathbf{A - 3 0}$ & 24,5 & 31,5 & 26,8 & 17,2 & 29,8 \\
\hline $\mathbf{A - 4 5}$ & 31,9 & 28,9 & 27,3 & 25,9 & 18,8 \\
\hline $\mathbf{A - 6 0}$ & 30,5 & 35,2 & 27,0 & 22,8 & 25,2 \\
\hline & & & & & \\
\hline REF. & 30,5 & 29,2 & 22,3 & 16,3 & 46,5 \\
\hline
\end{tabular}

Nota: Ft: Resistência à tração na flexão.

Figura 8 - Médias obtidas no ensaio de resistência tração na flexão dos compósitos com adição de resíduo, retardante comercial e amostra referência antes e após permanência em forno nas temperaturas de 125,225 e $325^{\circ} \mathrm{C}$

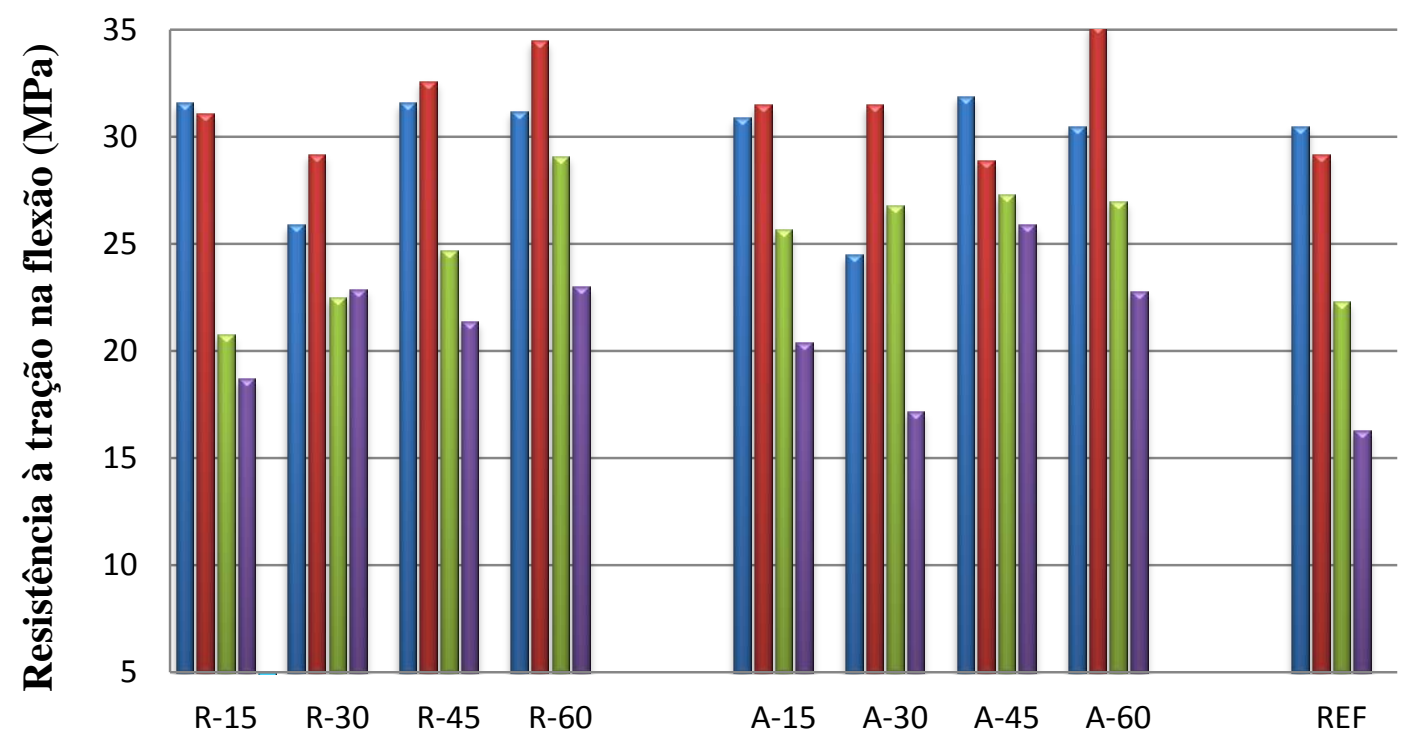

Tipos e teores de adição (\%)
$\square$ Tração flexão Temp ambiente
๑Tração flexão após 125 graus
$\square$ Tração na flexão após 225 graus $\square$ Tração na flexão após 325 graus

A partir da temperatura de $225^{\circ} \mathrm{C}$ constata-se que a perda da resistência mecânica inicia-se, apresentando uma perda ainda maior na temperatura de $325^{\circ} \mathrm{C}$. Observando a Tabela 7 , exceto pelos compósitos R30 e A45, nota-se que a perda de resistência mecânica aumenta nas amostras que apresentam menores quantidades de retardante de chamas, tanto no caso do retardante resíduo, como no caso do retardante comercial.
Sugere-se que esta redução considerável da perda de resistência mecânica à temperatura de $325^{\circ} \mathrm{C}$ deva-se à volatização do aglomerante polimérico, maior responsável pelo desempenho mecânico dos compósitos, entretanto o material mais suscetível à ação do calor.

Além disso, sugere-se que as adições de retardante de chamas agregaram aos compósitos uma 
resistência maior frente à ação do calor, especialmente quando comparados ao compósito referência.

De qualquer maneira, vale salientar que, apesar das perdas de resistência à tração na flexão ocorridas após a submissão das amostras à temperatura de $325^{\circ} \mathrm{C}$, os valores remanescentes, após permanência em forno, encontram-se próximos aos valores apresentados nos estudos consultados (REBEIZ, 1995; GORNINSKI; DAL MOLIN; KAZMIERCZAK，2007; RODRIGUES， 2007; GORNINSKI; KAZMIERCZAK， 2008， JO; PARK; PARK, 2008), salientando-se que os mesmos não foram submetidos ao calor nestas pesquisas.

\section{Ensaio de resistência ao calor: análise estatística}

Os dados da análise estatística, estão demonstrados na Tabela 8 e nas Figuras 9 e 10. Os resultados foram analisados quanto à influência do teor e do tipo de adição nos compósitos utilizados no estudo, bem como quanto às temperaturas as quais as amostras foram submetidas. Além disso, avaliou-se a interação entre as variáveis acima listadas, a fim de conhecerem-se os fatores significativos para o comportamento dos compósitos neste ensaio.

De acordo com a Tabela 8 , os resultados indicam que os fatores variação da temperatura, do teor de adição e a interação entre estes fatores exerceram influência sobre as composições em estudo $(\alpha=$ $0,000000)$ no que se refere ao ensaio de resistência ao calor. Os tipos de adição de retardante de chamas inseridos nos compósitos não mostraram ser influentes neste ensaio. Além disso, as interações entre os fatores, tipo de adição e temperatura e tipo de adição e teor de adição não se mostraram significativos no comportamento das amostras.

As Figuras 9 e 10 demonstram o comportamento dos compósitos com adição de retardante de chamas resíduo e retardante comercial consecutivamente, em todas as temperaturas trabalhadas e sem exposição ao calor, aqui denominado ambiente.

Através da Figura 9, verifica-se que, com relação ao PC com retardante resíduo, ocorreu um aumento de resistência mecânica referente ao processo de pós-cura, principalmente nos compósitos com maior teor de adição: 30, 45 e $60 \%$. Desta forma, e quando comparado com o comportamento do compósito referência, nota-se que o retardante resíduo apresentou influência importante na proteção dos compósitos frente ao calor, visto que, sem adição de retardante, o mesmo perdeu resistência, como já era esperado. Este fato ocorreu também em pesquisa de Browne, Adams e Frech (1975), onde os autores expuseram amostras de concreto polimérico a longos períodos de exposição a altas temperaturas e concluíram que o limite seguro, sem perdas de resistência, seria em torno de $60^{\circ} \mathrm{C}$ em caso de exposição contínua. Temperaturas entre 100 e $120^{\circ} \mathrm{C}$ seriam aceitáveis para períodos curtos, ou poderiam apresentar perda de resistência mecânica.

Tabela 8 - Análise de variância da resistência à ação do calor, conforme dados apresentados na Tabela 7

\begin{tabular}{c|c|c|c|c|c|c}
\hline VARIÁVEL & GLD & SQ & MQ & F & S & SIGNIFIC. \\
\hline Teor de adição (A) & 3 & 118,240 & 39,413 & 10,924 & 0,000 & SI \\
\hline Tipo de adição (B) & 1 & 11,455 & 11,455 & 3,175 & 0,081 & NS \\
\hline Temperatura (C) & 3 & 1021,571 & 340,524 & 94,380 & 0,000 & SI \\
\hline Interação (AB) & 3 & 6,127 & 2,042 & 0,566 & 0,640 & NS \\
\hline Interação (AC) & 9 & 153,228 & 17,025 & 4,719 & 0,000 & SI \\
\hline Interação (BC) & 3 & 30,289 & 10,096 & 2,798 & 0,050 & NS \\
\hline Erro & 49 & 176,793 & 3,608 & - & - & - \\
\hline
\end{tabular}


Figura 9 - Médias obtidas no ensaio de resistência tração à flexão dos compósitos com adição de retardante de chamas resíduo e amostra referência após permanência em forno nas temperaturas de 125,225 e $325^{\circ} \mathrm{C}$, bem como em temperatura ambiente

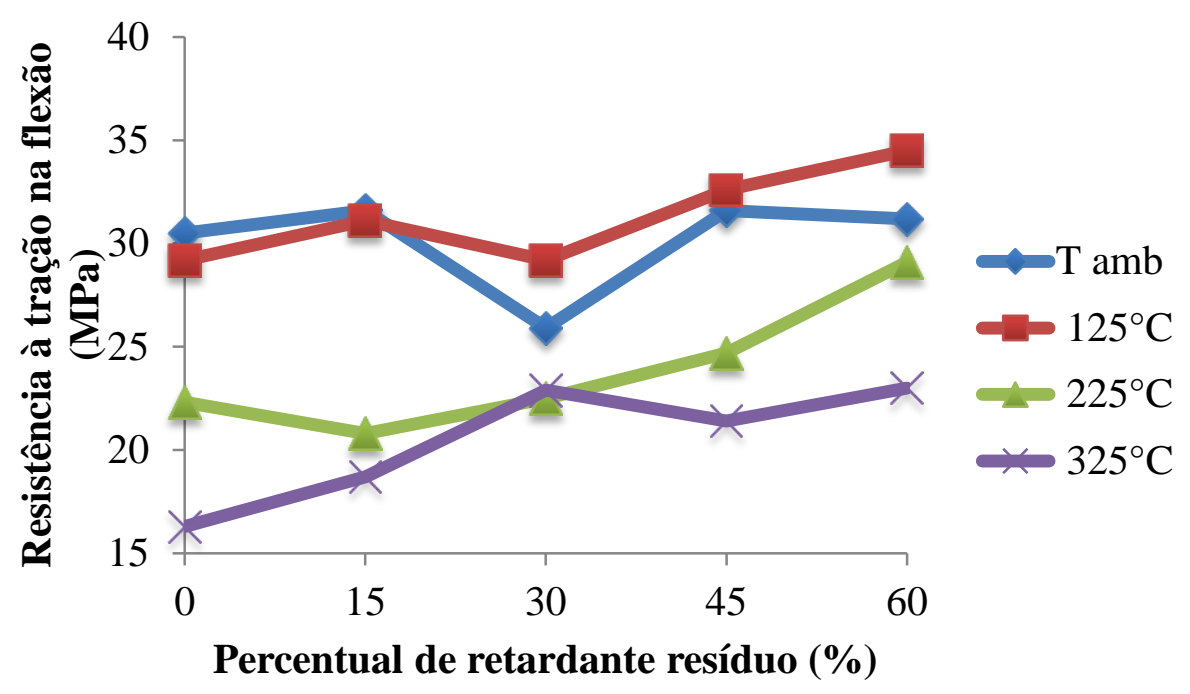

Davies, Wang e Wong (2006) testaram a influência da temperatura em painéis de plástico reforçado com fibras de vidro, produzidos com resina fenólica, e os submeteram as temperaturas de 60 , $90,120,150,200$ e $250^{\circ} \mathrm{C}$. Da temperatura ambiente para a temperatura de $250{ }^{\circ} \mathrm{C}$, a perda de resistência mecânica ficou na ordem de $91 \%$. De acordo com este estudo que incluía um comparativo com um modelo numérico de comportamento deste tipo de compósitos, os autores comprovaram que ocorreu uma concordância entre os resultados obtidos dos ensaios e os resultados calculados. No caso desta pesquisa, a perda de resistência mecânica não foi tão expressiva, pois os compósitos apresentam uma quantidade maior de elementos inorgânicos, agregado e filer, que conferem a eles uma maior eficiência frente à ação do calor.

Nesta pesquisa, com base nos dados apresentados na Tabela 5, observa-se que o compósito referência apresentou uma perda de $46,5 \%$ na sua resistência mecânica à temperatura de $325^{\circ} \mathrm{C}$, quando comparado com o resultado obtido em temperatura ambiente. Em relação às composições com o retardante resíduo, a menor perda de resistência mecânica foi observada para o compósito R30, o qual sofreu um decréscimo de apenas 11,5\% na sua resistência. Entretanto, observa-se que a maior perda de resistência mecânica observada nos compósitos com adição de retardante resíduo foi apresentada pelo compósito com $15 \%$ de adição. De qualquer maneira, o compósito R15 teve uma perda de resistência ainda inferior à apresentada pelo compósito referência, o que comprova a eficiência da adição do retardante resíduo para o fim proposto.

A Figura 10 apresenta um gráfico comparativo entre o comportamento do PC com adição de retardante comercial nas três temperaturas estudadas em comparação com o seu comportamento em temperatura ambiente.

Conforme comprovado pela análise estatística, o tipo de adição de retardante de chamas, resíduo ou comercial, não se mostrou significativo. Desta forma, observa-se que ambas as adições apresentaram um comportamento semelhante frente à ação do calor, principalmente quando comparadas ao compósito referência. No caso do retardante comercial, exceto pelo teor de $45 \%$ de adição, as outras composições também apresentaram um acréscimo de resistência mecânica após serem submetidas à temperatura de $125^{\circ} \mathrm{C}$, como foi o caso dos compósitos com adição de retardante resíduo.

Conforme ocorrido com o PC com adição de retardande resíduo, os compósitos com $15 \%$ de adição de retardante comercial também apresentaram a maior perda de resistência mecânica, o que confirma a significância apresentada pela análise estatística em relação à influência dos teores de retardante de chamas adicionados aos compósitos. Porém, conforme também ocorrido com a adição retardante resíduo, a perda de resistência do A15 $(33,92 \%)$ também foi inferior à perda do compósito referência, o qual apresentou $46,5 \%$ de perda em relação ao seu comportamento sem submissão ao calor. 
Ensaio de resistência ao calor: aspecto físico após exposição ao calor

Além dos fatores de resistência mecânica medidos neste ensaio de resistência ao calor, o aspecto físico superficial das amostras também apresentaram diferenças consideráveis após terem sido mantidas no forno. As Figuras 11a, 1b, 11c e $11 \mathrm{~d}$ mostram, nesta ordem, as amostras antes de ir ao forno, depois de submetidas à temperatura de $125^{\circ} \mathrm{C}$, após $225^{\circ} \mathrm{C}$ e após $325^{\circ} \mathrm{C}$.

Figura 10 - Médias obtidas no ensaio de resistência tração na flexão dos compósitos com adição de retardante comercial e amostra referência após permanência em forno nas temperaturas de 125, 225 e $325^{\circ} \mathrm{C}$, bem como em temperatura ambiente

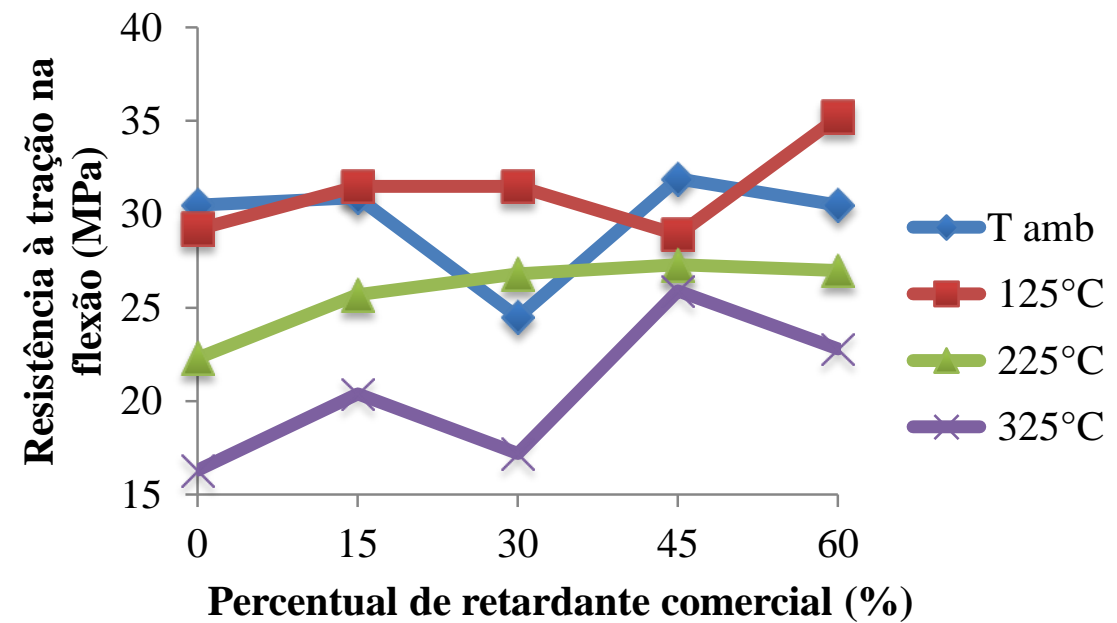

Figura 11 - Aspecto físico dos compósitos com adição de retardante residuo, retardante comercial e amostra referência antes (a) e após permanência em forno nas temperaturas de $125^{\circ} \mathrm{C}$ (b), $225^{\circ} \mathrm{C}$ (c) e $325^{\circ} \mathrm{C}(\mathrm{d})$

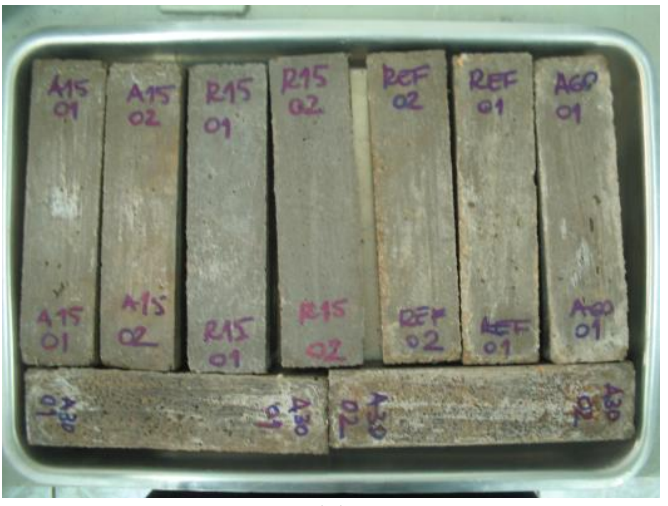

(a)

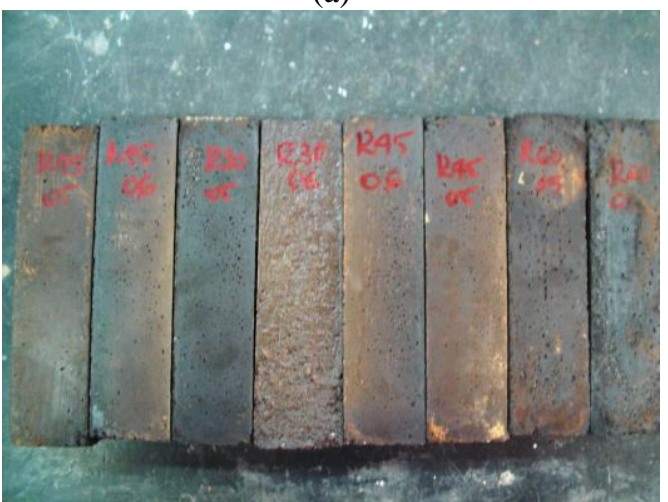

(c)

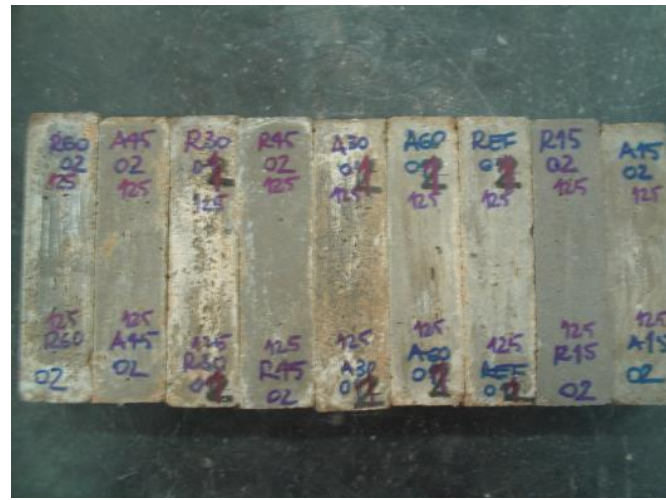

(b)

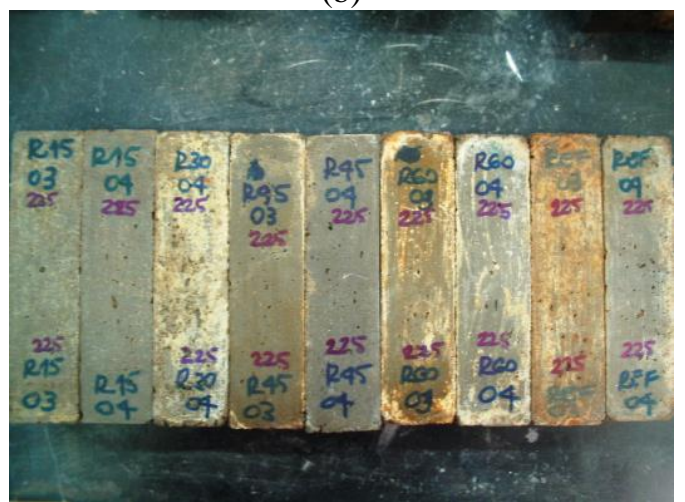

(d)

84 Gorninski, J. P.; Tonet, K.G. 
De acordo com a Figura 11, é possível observar que, em relação às amostras antes de ir ao forno, independente do tipo de adição ou sem ela, no caso da amostra referência, as amostras que foram submetidas às temperaturas de $125^{\circ} \mathrm{C}$ e $225^{\circ} \mathrm{C}$, aparentemente, não apresentaram sinais de degradação ou queima. As amostras apresentadas na Figura 10d, em compensação, apresentaram sinais de queima, tendo sua superfície escurecida e parte de suas bordas consumidas, com aparência de desgastadas, como se pode observar em detalhe na Figura 12. Durante o ensaio, somente os corposde-prova que ficaram no forno a $325^{\circ} \mathrm{C}$ apresentaram liberação de fumaça.

Todas as amostras, independente do tipo ou teor de adição apresentaram algum tipo de queima nas bordas (Figura 12a e 11b) e superfície com "buracos" (Figura 12c e 12d), o qual provavelmente deve-se à volatização da resina concentrada em alguns pontos. Notou-se, também, que as amostras mais queimadas, com aspecto mais escurecido, foram os compósitos referência, sem adições de retardante.
Desta forma, sugere-se que ambos os retardantes adicionados ao PC, independente do tipo, contribuíram para a preservação dos compósitos, tanto na manutenção da sua resistência mecânica após submissão ao calor, como no aspecto físico, mantendo um pouco mais a integridade da estrutura.

\section{Conclusões}

Os concretos poliméricos produzidos nesta pesquisa apresentaram altos valores de resistência para o ensaio de tração na flexão, aproximando-se dos $30 \mathrm{MPa}$. Os valores obtidos foram superiores aos apresentados pela maioria dos concretos poliméricos citados na literatura, onde os valores estão em torno dos $20 \mathrm{MPa}$.

A análise estatística indicou que há diferenças significativas entre os teores das adições utilizadas, porém demonstra que não há significância quanto ao tipo de adição, bem como na interação entre estes fatores, o que viabiliza a utilização do resíduo em detrimento ao retardante comercial.

Figura 12 - Aspecto físico dos compósitos após permanência em forno nas temperaturas de $325^{\circ} \mathrm{C}(\mathrm{a})$, (b), (c) e (d)

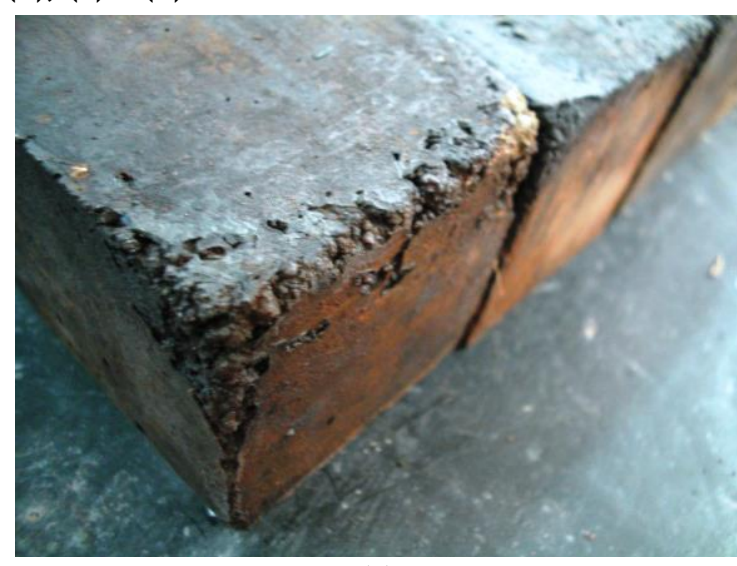

(a)

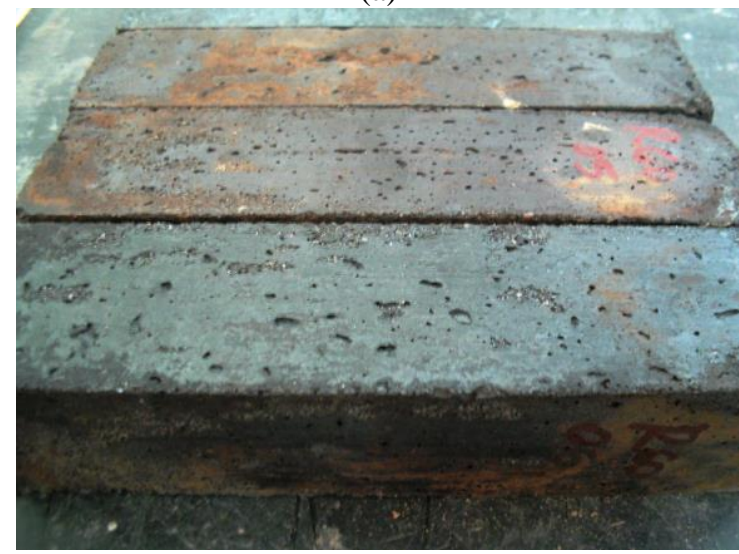

(c)

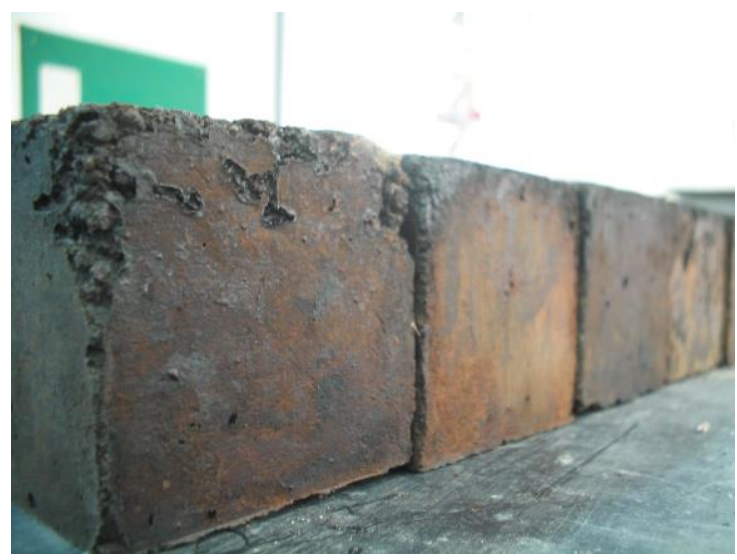

(b)

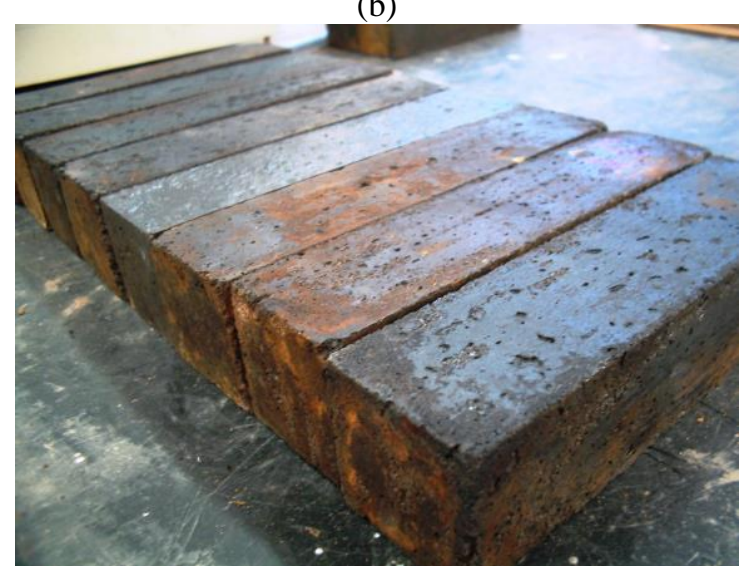

(d) 
As adições de retardante de chamas, resíduo e comercial, agregaram aos compósitos uma maior resistência frente à ação do calor, especialmente quando comparados ao compósito referência.

Após a submissão ao forno em temperatura de $125^{\circ} \mathrm{C}$ por uma hora, as composições R30, R45, R60, A15, A30 e A60 apresentaram um aumento de resistência à tração na flexão, atribuído ao processo de pós-cura, quando comparados aos compósitos que permaneceram em temperatura ambiente.

$\mathrm{O}$ aumento da temperatura para 225 e $325^{\circ} \mathrm{C}$ teve efeito significativo sobre a perda de resistência dos compósitos, porém os valores remanescentes após a submissão ao forno a $325^{\circ} \mathrm{C}$ encontram-se próximos aos valores apresentados na literatura. Os compósitos com maior adição de retardante $(60 \%)$, por exemplo, independente do tipo, apresentaram resistência à tração na flexão remanescente com valores de 23,0 $\mathrm{MPa}$ (R60) e 22,8 MPa (A60). A maior redução de resistência, como poderia se esperar, foi apresentada pelo compósito referência o qual apresentou uma perda de 46,5\% na sua resistência à tração na flexão.

A análise estatística indicou que os fatores variação da temperatura, do teor de adição e a interação entre estes fatores exerceram influência sobre as composições em estudo $(\alpha=0,00)$ no que se refere ao ensaio de resistência ao calor. Os tipos de adição de retardante de chamas inseridos nos compósitos não mostraram ser influentes neste ensaio. Além disso, as interações entre os fatores, tipo de adição e temperatura e tipo de adição e teor de adição não se mostraram significativos no comportamento das amostras.

No geral, e levando-se em consideração os resultados demonstrados pela análise estatística conclui-se que, o retardante de chamas resíduo alumina de polimento apresentou-se como alternativa eficiente em substituição ao retardante comercial alumina trihidratada nos compósitos de concreto polímero com os demais componentes propostos neste estudo.

\section{Referências}

ABDEL-FATTAH, H.; EL-HAWARY, M. M. Flexural Behavior of Polymer Concrete.

Construction and Building Materials, v. 13, n. 5, p. 253-262, 1999.

AGNELLI, J.A.M. Reciclagem de Polímeros: situação brasileira. Polímeros: Ciência e

Tecnologia, v. 6, n. 4, p. 9-18, out./dez. 1996.
ALBEMARLE CORPORATION. 2007. Ficha Técnica da Alumina Trihidratada. Bélgiaca: Albemarle Corporation, 2007.

ALCOA. Catálogo de Produtos Alcoa Para Indústria Química e de Polímeros. São Paulo: Alcoa Alumínio S.A., 2004.

ALCOA. [Produto]. 2007. Disponível em: <http://www.alcoa.com/brazil/pt/product_category .asp?cat_id=873>. Acesso em: 03 jan. 2008.

ARAASHLAND. [Produto]. 2008. Disponível em: <http://www.araquimica.com.br/site2008/produtos /14.0.pdf>. Acesso em: 15 jan. 2009.

ASSOCIAÇÃO BRASILEIRA DE NORMAS TÉCNICAS. NBR 12142: concreto: determinação da resistência à tração na flexão em corpos-deprova prismáticos. Rio de Janeiro, 1991.

\section{ASSOCIAÇÃO BRASILEIRA DE NORMAS} TÉCNICAS. NBR 5738: concreto: procedimento para moldagem e cura de corpos-de-prova. Rio de Janeiro, 1994.

ASSOCIAÇÃO BRASILEIRA DE NORMAS TÉCNICAS. NBR 7211: agregados para concreto: especificação. Rio de Janeiro, 2005.

ASSOCIAÇÃO BRASILEIRA DE NORMAS TÉCNICAS. NBR NM 23: cimento portland e outros materiais em pó: determinação da massa específica. Rio de Janeiro, 2000.

ASSOCIAÇÃO BRASILEIRA DE NORMAS TÉCNICAS. NBR NM 248: agregados: determinação da composição granulométrica. Rio de Janeiro, 2001.

\section{ASSOCIAÇÃO BRASILEIRA DE NORMAS} TÉCNICAS. NBR NM 52: agregado miúdo: determinação massa específica e massa específica aparente. Rio de Janeiro, 2002.

BIGNOZZI, M. C.; SACCANI, A.; SANDROLINI, F. New Polymer Mortars Containing Polymeric Wastes: part 1: microestruture and maechanical properties. Composites: Part A, v. 31, p. 97-106, 2000.

BROWNE, R. D.; ADAMS, M.; FRECH, E. L. Experience in the Use of Polymer Concrete in the Building and Construction Industry. In: International Congress on Polymers in Concrete, Lancaster, 1975. Proceedigns... Lancaster, 1975.

BIGNOZZI, M. C.;

DAVIES, J. M.; WANG, Y. C.; WONG, P. M. H. Polymer Composites in Fire. Composites: Part A, v. 37, p. 1131-1141, 2006. 
FOWLER, D. Polymers in Concrete: where have we been and where are we going? In:

INTERNATIONAL CONGRESS ON POLYMERS IN CONCRETE AND ICPIC/ICRI INTERNATIONAL CONCRETE REPAIR WORKSHOP, 10., Honolulu, 2001. Proceedings... Honolulu, 2001.

FU, S. et al. Effects of Particle Size, Particle/Matrix Interface Adhesion and Particle Loading on Mechanical Properties of Particulate: polymer composites. Composites: Part B, v. 39, p. 933-961, 2008.

GOPAL, R. Polymer Concrete Composites for Enhancement of Mobility of Troops in Desert Operations. Materials Sience and Engineering B, v. 132, n. 1/2, p. 129-133, 2006.

GORNINSKI J. P. Estudo da Influência das Resinas Poliéster Isoftálica e Ortoftálica e do Teor de Cinza Volante nas Propriedades Mecânicas e Durabilidade do Concreto Polímero. Porto Alegre, 2002. 167 f. Tese (Dissertação em Engenharia Civil) - Programa de Pós-Graduação em Engenharia Civil, Universidade Federal do Rio Grande do Sul, Porto Alegre, 2002.

GORNINSKI J. P. Investigação do Comportamento Mecânico do Concreto Polimero de Resina Poliéster. Porto Alegre, 1999. 103 f. Dissertação (Mestrado em Engenharia Civil) - Programa de Pós-Graduação em Engenharia de Minas e Metalurgia, Universidade Federal do Rio Grande do Sul, Porto Alegre, 1996.

GORNINSKI, J.; DAL MOLIN, D.; KAZMIERCZAK, C. Study of the Modulus of Elasticity of Polymer Concrete Compounds and Comparative Assessment of Polymer Concrete and Portland Cement Concrete. Cement and Concrete Research, v. 34. p. 2091-2095, 2004.

GORNINSKI, J.; KAZMIERCZAK, C. Avaliação da Resistência Química de Concretos Poliméricos em Ambientes Agressivos. Ambiente Construído, Porto Alegre, v. 8, n. 1, p. 63-71, jan./mar. 2008.

IGNACIO, C.; FERRAZ V.; ORÉFICE, R.L. Reciclagem Química de PET Para Aplicações em Concreto de Poliéster. In: CONGRESSO BRASILEIRO DE POLÍMEROS, 7., Belo Horizonte, 2003. Anais... Belo Horizonte, 2003.

JO, B.; PARK, S.; PARK, J. Mechanical Properties of Polymer Concrete Made With Recycled PET and Recycled Concrete Aggregates. Construction and Building Materials, v. 22, n. 12, p. 2281-2291, 2008.
JO, B.; TAE, G.; KIM, C. Uniaxial Creep Behavior and Prediction of Recycled-PET Polymer Concrete. Construction and Building Materials, v. 21, p. 1552-1559, 2007.

MAHDI F.; KHAN A. A.; ABBAS, H. Physiochemical Properties of Polymer Mortar Composites Using Resins Derived From PostConsumer PET Bottles. Cement and concrete composites, v. 29, n. 3, p. 241-248, mar. 2007.

MARÍN, C. G. et al. Fire Reaction of a Polyester Polymer Mortar. Journal of Polymer Engineering, p. 353-368, 2003.

MEHTA K. P.; MONTEIRO P. J. M. Concreto: estrutura, propriedades e materiais. São Paulo. PINI, 1994.

ORAK, S. Investigation of Vibration Damping on Polymer Concrete With Polyester Resin. Cement and Concrete Research, v. 30, n. 2, p. 171-174, 2000.

PINTO, M. R. O. et al. Influence of Addition and Chemical Change of a Nanoparticulated Mineral Load on the Mechanical Properties and Termic Aging of Composites Polyurethane/Sisal.

Polymers, v. 15, n. 4, p. 313-319, 2005.

RABELlo, M. S. Aditivação de Polímeros. São Paulo: Artliber, 2000.

REBEIZ, K. S. Precast Use of Polymer Concrete Using Unsaturated Polyester Resin Based on Recycled PET Waste. Construction and Building Materials, v. 10, n. 3, p. 215-220, 1995.

REICHHOLD. [Ficha técnica de produtos.]. São Paulo: Reichhold do Brasil, 2004.

RODRIGUES, G. Avaliação das Propriedades Mecânicas de Compostos de Concreto Polímero Produzidos Com Materiais Reciclados. São Leopoldo, 2007. 118 f. Trabalho de Conclusão de Curso (Curso de Engenharia Civil) - Universidade do Vale do Rio dos Sinos, São Leopoldo, 2007.

SILVA, N. G.; BUEST, G.; CAMPITELI, V. C. Argamassas Com Areia Britada: influência dos finos e da forma das partículas. In: SIMPÓSIO BRASILEIRO DE TECNOLOGIA DE ARGAMASSAS, 6.; INTERNATIONAL SYMPOSIUM ON MORTARS TECHNOLOGY, Florianópolis, 2005. Anais... Florianópolis, 2005.

TROMBINI, R. C. Desenvolvimento e Caracterização de Composições de Polipropileno/Cargas Retardantes de Chamas. 233 f. São Carlos, 2003. Tese (Doutorado em Engenharia de Materiais) - Programa de PósGraduação em Ciência e Engenharia de Materiais, Universidade Federal de São Carlos, São Carlos, 2004. 
TYBERG, C. S. et al. Tough, Void-Free, Flame

Retardant Phenolic Matrix Materials.

Construction and building materials, v. 13, n. 6 , p. 343-353, 1999.

Jane Proszek Gorninski

Departamento de Ciências do Mar | Universidade Federal de São Paulo | Av. Almirante Saldanha da Gama, 89, Ponta da Praia | Santos - SP - Brasil | CEP 11030-400 | Tel.: (13) 3523-5061 | E-mail: proszek@hotmail.com.br

\section{Karina Guerra Tonet}

Karina Tonet Arquitetura | Rua Barão de Ubá, 123/202 | Porto Alegre - RS - Brasil | CEP 90450-099 | Tel.: (51) 3012-9295 |

E-mail: contato@karinatonet.com.br

Revista Ambiente Construído

Associação Nacional de Tecnologia do Ambiente Construído

Av. Osvaldo Aranha, $99-3^{\circ}$ andar, Centro

Porto Alegre - RS - Brasil

CEP $90035-190$

Telefone: +55 (51) 3308-4084

Fax: +55 (51) 3308-4054

www.seer.ufrgs.br/ambienteconstruido

E-mail: ambienteconstruido@ufrgs.br 